\title{
FT-IR and FT-Raman Studies of Colloidal ZnS
}

\author{
RUNE GÄRD
}

May 1995 


\section{FT-IR and FT-Raman Studies of Colloidal ZnS}

\section{Rune Gärd}

Division of Inorganic Chemistry Luleå University of Technology S-971 87 Luleå, Sweden

May 1995 


\section{CONTENTS}

BACKGROUND 3

INTRODUCTION 3

Zinc Sulphide 3

Flotation 5

Vibrational Spectroscopy 6

IR 6

FT-IR Spectroscopy 7

Detectors and Sources in IR 9

Sampling Techniques in FT-IR 11

Raman Scattering 13

Detectors and Lasers in Raman $\quad 14$

Surface Reactions 15

RESEARCH OBJECTIVE AND SCOPE 16

EXPERIMENTAL 17

RESULTS AND DISCUSSION 20

Acidic and Alkaline Sites at the ZnS/water Interface (Paper I)

Sorption of Amylxanthate (Paper II) 24

CONCLUSIONS AND FUTURE PLANS 30

ACKNOWLEDGEMENTS 30

REFERENCES 31

Paper I: FT-IR and FT-Raman Studies of Colloidal ZnS

1. Acidic and Alkaline Sites at the $\mathrm{ZnS} /$ water Interface

Rune Gärd, Zhong-Xi Sun and Willis Forsling

J. Colloid Interface Sci. 169, 393 (1995)

Paper II: FT-IR and FT-Raman Studies of Colloidal ZnS

2. Sorption of Amylxanthate at the $\mathrm{ZnS} /$ water Interface

Rune Gärd, Zhong-Xi Sun and Willis Forsling

To be published 


\section{BACKGROUND}

An impressing amount of knowledge, concerning surface complexation at the sulphide mineral/water interface, has been gathered during the past years. This knowledge has been brought about mainly by the use of potentiometric titrations. Vibrational spectroscopy can provide more direct evidence for surface reactions, than can be obtained by traditional titrations. However, these reactions mainly involve one monolayer, and can be troublesome to study with spectroscopic methods. Therefore, instead of using ground minerals, we have chosen to use precipitated zinc sulphide in order to obtain a large surface to volume ratio. This way the signal from the surface species will not be drowned in the signal from the bulk. Another advantage with synthetic $\mathrm{ZnS}$ is that it doesn't contain iron, which most native zinc sulphides do (iron interferes with a $1064 \mathrm{~nm}$ laser [1]). Pure zinc sulphide is IR-transmitting and white, which is also advantageous for vibrational spectroscopic measurements. We believe that $\mathrm{ZnS}$ could serve as a model for other sulphides, that are not so well suited for spectroscopy.

Flotation is a very important industrial process and has hence attained much interest from researchers. The key step in this process is the adsorption of collectors onto mineral surfaces. One of the main scientific interests has been to find out in what way the collector is adsorbed at the mineral and how and if the collector molecule is altered in that process. Much less interest has been directed towards possible changes in the mineral itself. We have therefore decided, also to investigate how and if the acidic and alkaline sites at the mineral surface are altered upon sorption of xanthate ions.

\section{INTRODUCTION}

\section{Zinc sulphide}

Zinc sulphide occurs in two dimorphous forms; sphalerite ( $\beta-\mathrm{ZnS})$ and wurtzite ( $\alpha-\mathrm{Zns})$. Sphalerite is the stable form of $\mathrm{ZnS}$ and crystallises 
from weakly alkaline to weakly acid solutions while wurtzite crystallises from acid solutions [2]. At temperatures above $1020{ }^{\circ} \mathrm{C}$ sphalerite is altered to wurtzite.

Sphalerite is the most important zinc mineral and is often associated with galena in the deposits. Cadmium can replace zinc in sphalerite, as a matter of fact the whole annual production of cadmium is obtained as a by-product of zinc smelting. Sphalerite has a structure analogous to diamond with each zinc atom co-ordinated to four sulphur atoms and each sulphur atom co-ordinated to four zinc atoms. The $\mathrm{ZnS}$ tetrahedral layers show a face-centred cubic stacking (see Fig.1).

Wurtzite is of far less importance and can be found in various sulphidic ores. Like in sphalerite $\mathrm{Zn}$ is often substituted by $\mathrm{Fe}, \mathrm{Cd}$ or $\mathrm{Mn} . \mathrm{CdS}$ is found together with wurtzite as greenockite. Wurtzite has a hexagonal stacking of the $\mathrm{ZnS}$ tetrahedral layers [3] (see Fig.2).

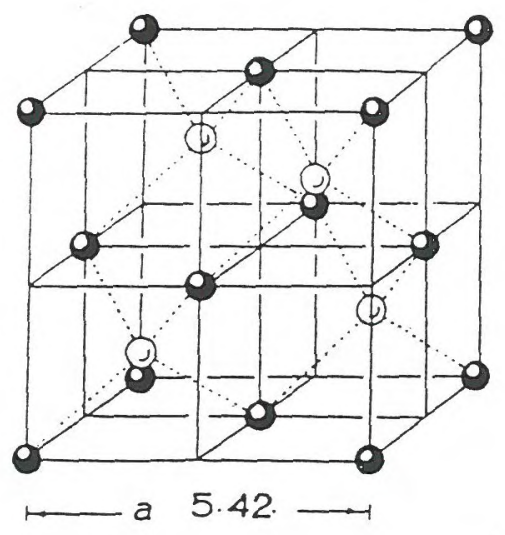

Fig. 1. Sphalerite

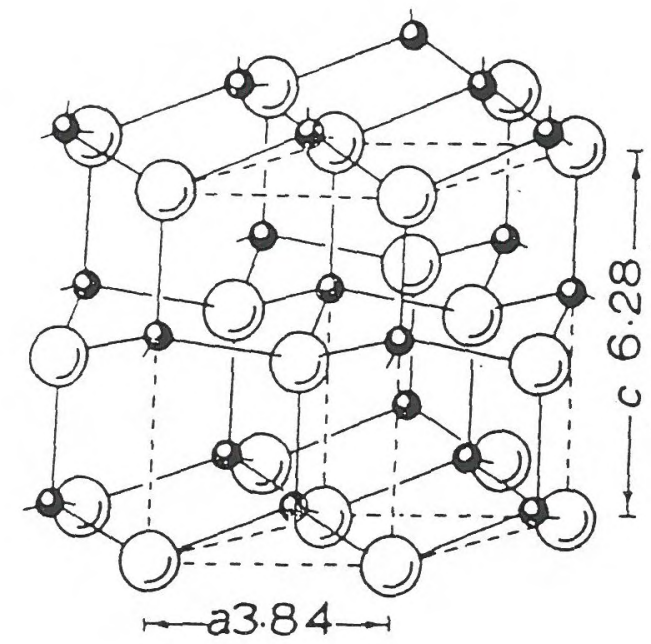

Fig. 2. Wurtzite 


\section{Flotation}

The method of flotation was developed at the beginning of this century and it has since then become the single most important method of mineral separation. Initially designed for sulphide ores, the method has now expanded to include oxides, such as hematite and non-metallic ores, such as fluorite and fine coal. The tonnage of the materials floated in the world exceeds 1000 million tonnes per year. The efficiency and selectivity of the flotation process have made possible the beneficence of low-grade and complex ore bodies.

The overall principle of flotation is the selective hydrophobation of valuable minerals by the action of certain surface active molecules, so called collectors. Air bubbles, stabilised by frothers, will float the hydrophobic particles while the hydrophilic ones will remain in the suspension. Several reagents are added to the flotation pulp, to be selectively adsorbed at the mineral/water interface. The reagents are required to accentuate the difference in surface and chemical properties of the minerals. Depressants are reagents added to prevent flotation of unwanted minerals by making them hydrophilic and activators are used to promote collector adsorption onto a valuable mineral. Both types of reagents are generally referred to as flotation modifiers.

Xanthates are the most commonly used collectors in sulphide mineral flotation [4]. They are derivatives of carbonic acid where two of the oxygen atoms have been substituted by sulphur atoms and one hydrogen atom by an alkyl group. Thus, a general formula for a xanthate ion is $\mathrm{R}-\mathrm{O}-\mathrm{C}-\mathrm{S}_{2}^{-}$where $\mathrm{R}$ denotes an alkyl group.

By varying the length and geometry of the carbon chain one can design a xanthate molecule with desired characteristics with respect to selectivity and power. On the whole one can say that a shorter carbon chain increases the selectivity while a longer carbon chain gives a more powerful collector. Thus, for the selective flotation of $\mathrm{Cu}-\mathrm{Zn}, \mathrm{Pb}-\mathrm{Zn}$ and $\mathrm{Cu}-\mathrm{Pb}-\mathrm{Zn}$ sulphides one uses ethyl xanthate. Propyl and butyl xanthates 
are more powerful but less selective collectors for these sulphides. The latter xanthates are also used for $\mathrm{Au}, \mathrm{Ag}, \mathrm{Co}, \mathrm{Ni}, \mathrm{Sb}$ sulphides and pyrite. For bulk flotation of sulphides amyl and hexyl xanthates are used. These are the most powerful but least selective ones [5].

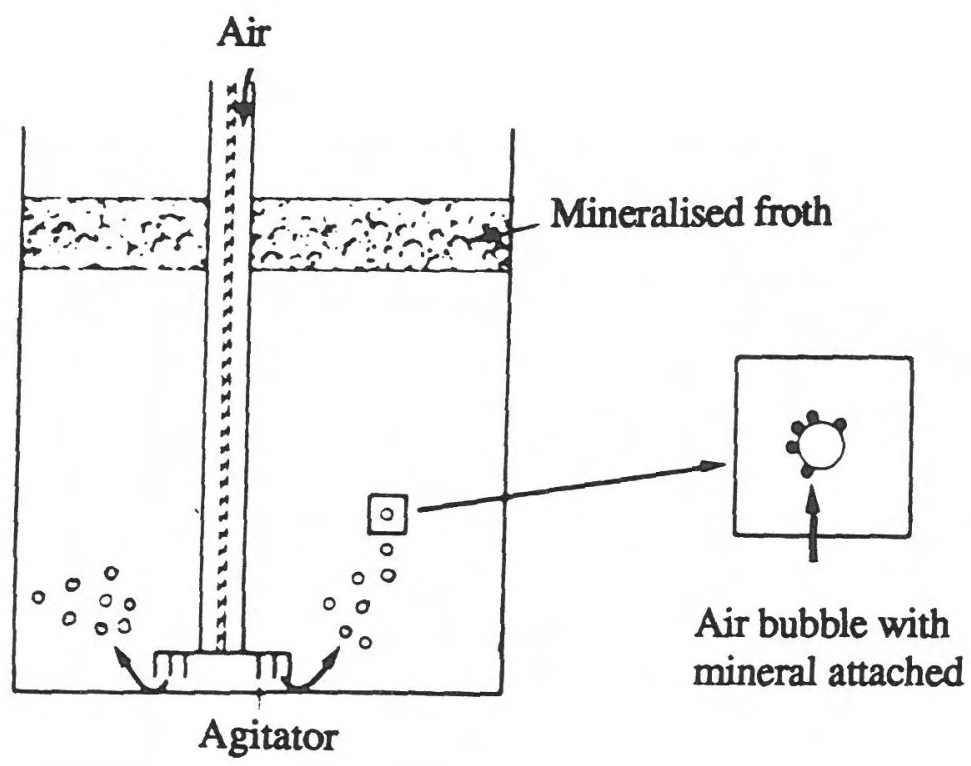

Fig. 3. Flotation cell.

\section{Vibrational Spectroscopy}

IR

Scientific infrared spectroscopy emerged at the end of the last century. However, the difficulties in building good instruments didn't give much hope for the infrared technique to become a major analytical method. After 1945, when the servo amplifiers were invented, commercial infrared spectrometers have become available and the technique has become a recognised analytical method in all the branches of chemistry. 
The Michelson type interferometer and the Fourier Transform together with modern computers have further increased the versatility and accuracy of the IR spectrometer [6].

The infrared region of the electromagnetic spectrum extends from the red end of the visible spectrum out in the invisible region. The region includes radiation at wavenumbers between 14000 and $20 \mathrm{~cm}^{-1}$. The most interesting part of the spectrum ranges from 4000 to $200 \mathrm{~cm}^{-1}$ (the mid-IR region). Atoms or atomic groups in molecules are in continuos motion with respect to each other. Infrared spectrometry involves the twisting, bending, rotating and vibrational motions of atoms in a molecule. In a spectrometer the molecules are struck with a whole range of infrared frequencies. Only certain parts of the spectrum can be absorbed by the molecules and these frequencies match the frequencies of the molecules' vibrations. These frequencies are uniquely characteristic of the functional groups comprising the molecules and of the overall configuration of the atoms as well. The absorbed frequencies depend on the frequency at which the molecule is vibrating, while the intensity of the absorption depends on the effectiveness with which the infrared photon is transferred to the molecule, which in turn depends on the change in dipolar moment that is the result of molecular vibration.

\section{FT-IR Spectroscopy}

The traditional prism and grating dispersive spectrophotometers have several disadvantages amongst which the slow scanning speed, low signal to noise ratio $(\mathrm{S} / \mathrm{N})$ and difficulties in measuring low transmittance values are the most pronounced. In addition the sensitivity at low wavenumbers is often poor and it is not possible to get high resolution over a wide frequency range.

The Fourier Transform Spectrometer doesn't suffer from any of these drawbacks. In this instrument light of all wavelengths strikes the Michelson interferometer (see Fig 4) where a beamsplitter, ideally, 
divides the light in two equally intense beams. One beam is reflected to a fixed mirror where it is again reflected back to the beamsplitter. The other beam passes the beamsplitter and is reflected in a moveable mirror which is controlled by a laser beam. When the two beams once again reach the beamsplitter half of the light is reflected back to the source and the other half is reflected to the sample and then to a detector. The recombined beams can either interfere constructively or destructively depending on the phase difference of the two optical paths. The resulting interferogram is defined as a relationship between the energy and the path difference. To get a spectrum, which is the amount of transmitted energy as a function of wavenumber, the interferogram is Fourier transformed using the Cooley-Tuckey algorithm.

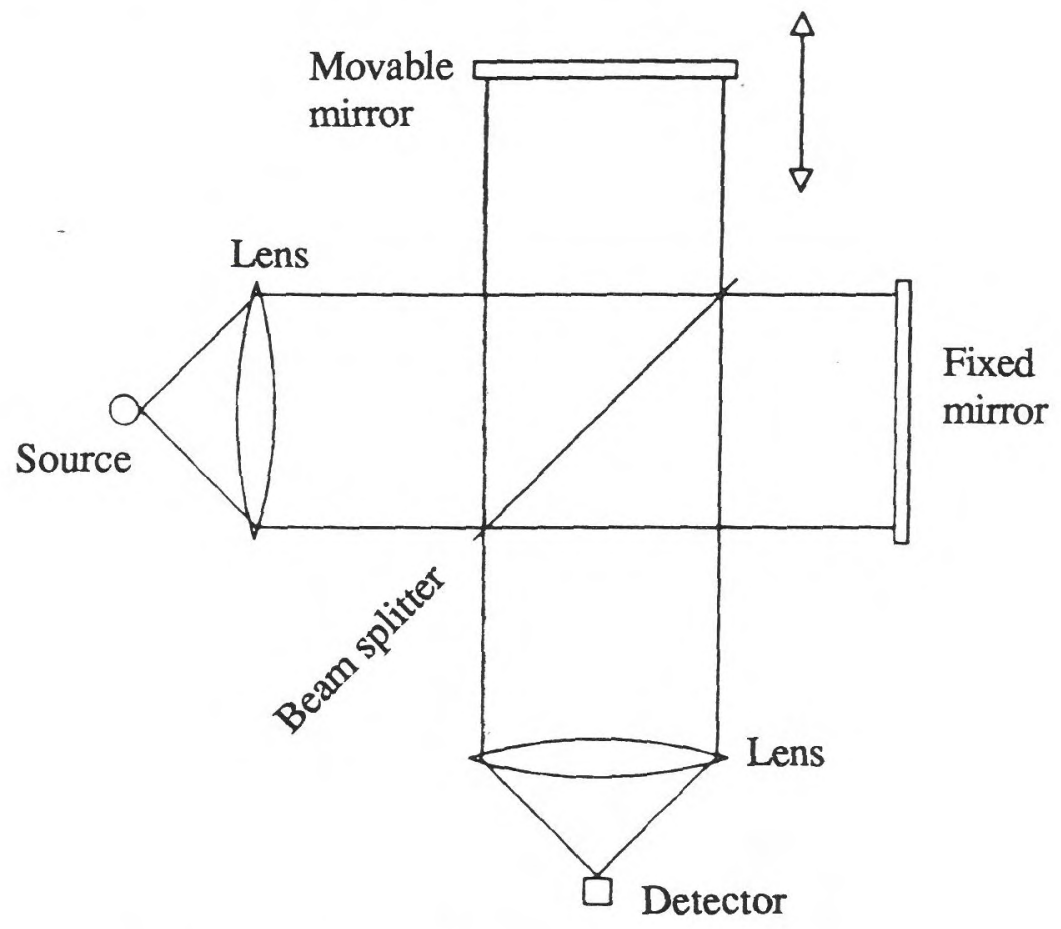

Fig. 4. Schematic of a Michelson interferometer. 
The major advantages with FT-IR are [7]:

1. Felgett's advantage concerns the speed at which spectra can be acquired and the signal to noise ratio. Since all frequencies are measured at the same time, one spectrum can be recorded at the same time that it takes to record one resolution element on a dispersive instrument. The $\mathrm{S} / \mathrm{N}$ ratio will be improved by the square root of the number of resolution elements being examined.

2. The Jacquinot advantage concerns the amount of energy that is let through. The energy is determined only by the size of the mirrors in the interferometer, as no entrance or exit slits are used.

3. The Connes advantage concerns the stability in the frequency readings. Because a laser is used to control the position of the moving mirror the accuracy of the frequency readings is much improved.

\section{Detectors and Sources in IR}

In an infrared detector the energy of the radiation is changed to electrical energy which can then be processed to generate a spectrum. The two most common types of detectors are thermal detectors and selective detectors. One of the thermal type is the pyroelectric detector which consists of a thin pyroelectric crystal such as triglycine sulphate (TGS) or deuterated triglycine sulphate (DTGS). If such a material is electrically polarised in an electric field, it retains a residual electric polarisation after the field is removed. The residual polarisation is sensitive to changes in the temperature. Electrodes on the crystal faces collect the charges so the device acts as a capacitor across which a voltage appears, the amount of which is sensitive to the temperature of the device. The pyroelectric detector operates at room temperature. Being a thermal device, it possesses essentially flat wavelength response ranging from the near infrared through the far infrared. It can handle signal frequencies of up to several thousand Hertz and hence is well 
suited for Fourier transform infrared spectrometers. The TGS detector is rather insensitive but covers the whole mid-IR range.

The most important type of selective detector is the photoconductive cell which has a very rapid response and a high sensitivity. An example is the Mercury Cadmium Telluride detector (MCT) which is cooled with liquid nitrogen. These detectors utilise photon energy to promote bound electrons in the detector material to free states, which results in increased electrical conduction. There is a long wavelength limit to the response however, because photons with wavelengths longer than a certain limit will have insufficient energy to excite the electrons [8]. There are three types of MCT detectors; high-sensitivity, narrow-range $\left(\bar{v}_{\min }=750 \mathrm{~cm}^{-1}\right)$, medium sensitivity, intermediate-range $\left(\bar{v}_{\min }=600\right.$ $\left.\mathrm{cm}^{-1}\right)$ and low-sensitivity, wide-range $\left(\bar{v}_{\min }=450 \mathrm{~cm}^{-1}\right)$ [9].

Since infrared light is heat radiation, any hot source is an emitter of IR. There are three criteria that should be taken into account when the material and design of the source are chosen; the total energy radiated should be as great at possible, the material should be as close as possible to a black body and finally the dimensions of the source should be small and with the highest possible surface brightness. The higher the temperature of the source, the more intense is the total radiation emitted and the lower the wavelength of the peak emission:

$$
\mathrm{W}=\sigma \cdot \mathrm{T}^{4}
$$

At about $1000 \mathrm{~K}$, a black body glows red. Between 1000 and $1800 \mathrm{~K}$, the colour changes from red to orange and yellow and above $2200 \mathrm{~K}$ the emission appears white since all visible colours are represented in the emitted spectrum. Thus it may appear at first that $1000 \mathrm{~K}$ would be ideal for IR spectroscopy since its peak emission occurs in the infrared spectral region. However, since the total energy radiated increases with the fourth power of temperature, a source as hot as possible is advantageous as an infrared source, and the light emitted in the visible or even ultraviolet range is discarded [10]. 
Sampling Techniques in FT-IR

Various techniques are used to obtain infrared spectra from solid samples. Depending on the nature of the sample or what frequency range that is expected to be of greatest interest and possible water content, one can choose among three methods.

Mulls can me made by mixing a few milligrams of the finely ground sample with a small amount of mineral oil to get a thick paste. The paste is then evenly spread between two IR-transmitting windows. As mulling agent one can choose Nujol which itself has $\mathrm{CH}$ stretches in the region between 3000 and $2800 \mathrm{~cm}^{-1}$ and $\mathrm{CH}$ bending modes between 1460 and $1375 \mathrm{~cm}^{-1}$. Another alternative is a halogenated oil such as Halocarbon or Fluorolube which contains $\mathrm{CF}_{2}$ and $\mathrm{CFCl}$ groups but no $\mathrm{CH}$. These have no bands from 4000 to $1300 \mathrm{~cm}^{-1}$ but exhibit strong bands below $1300 \mathrm{~cm}^{-1}$. To obtain the whole infrared spectrum of the sample one can run two spectra, one using Fluorolube and one using Nujol.

Potassium Bromide Disks are made by mixing a few milligrams of very finely ground sample with 50 to 100 parts of dry $\mathrm{KBr}$ powder and pressing the mixture to a disk in a hydraulic press. An advantage with this method over mull methods is that $\mathrm{KBr}$ has no absorption bands above $400 \mathrm{~cm}^{-1}$. One disadvantage is that $\mathrm{KBr}$ is hygroscopic which can result in water bands in the spectrum.

Attenuated Total Reflection (ATR) works according to Fig. 5. The IR beam is totally reflected within a transparent crystal (typically ZnSe or KRS-5). The sample, which may be solid or a solution, is in contact with this crystal surface. Since the infrared data are collected from the reflected and not the transmitted light, samples that are opaque can be investigated. It is also possible to run spectra on water-containing pastes since the path through the water is very short $(\sim 1 \mu \mathrm{m})$.

In the Diffuse Reflectance (DRIFT) technique a small amount (1-5\%) of the finely ground sample is diluted with dry $\mathrm{KBr}$ powder and placed in a small container where source radiation strikes it and is diffusely 
reflected in various directions. This radiation is collected and measured by the spectrometer. The spectrum is ratioed against a reference spectrum of pure powdered $\mathrm{KBr}$. The spectrum is often processed by a computer using a function $f\left(R_{\infty}\right)$ derived by Kubelka and Munk, which changes the reflectance spectrum into one resembling a linear absorbance spectrum:

$f\left(R_{\infty}\right)=\frac{\left(1-R_{\infty}\right)^{2}}{2 R_{\infty}}=\frac{k}{s}$

$$
R_{\infty}=\frac{R_{\infty}(\text { sample })}{R_{\infty}(\text { reference })}
$$

Here $R_{\infty}$ is the reflectance of a thick scattering layer, $k$ the molar extinction coefficient and $s$ a scattering coefficient which is a function of particle size. This technique is sensitive to the particle size and it demands the size to be uniformly distributed. DRIFT is a simple technique but is normally not used for quantitative measurements [11]. If multivariate calibration is used the technique can also offer quantitative estimations [12].

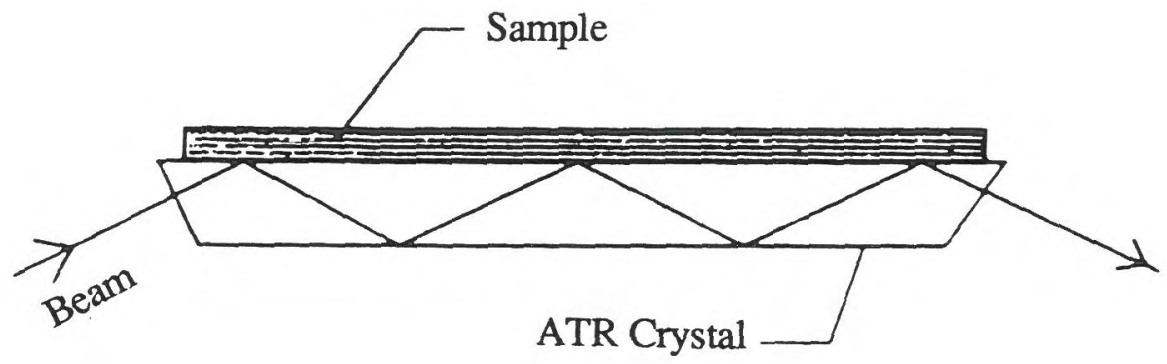

Fig. 5. Experimental arrangement for ATR spectroscopy. 


\section{Raman Scattering}

Raman scattering was first predicted by A. Smekal in 1923 and experimentally observed by Sir C.W. Raman five years later. The Raman spectroscopy lived in relative obscurity until the development of lasers and modern computers and the "rediscovery" of the Fourier Transform (FT). FT-Raman spectroscopy has allowed the sampling of spectra in a fast and reproducible way and has become an increasingly important method for the determination of the composition, structure and properties of substances [13].

Raman spectra are related to infrared spectra but they have a quite different origin and therefore they can provide complementary information about molecular structure. When monochromatic light is scattered by molecules, a small fraction of the scattered light is observed to have a different frequency from that of the irradiating light; this is known as the Raman effect. It arises when a beam of intense monochromatic light passes through a sample that contains molecules that can undergo a change in molecular polarisability as they vibrate. The vast majority of the collisions between the photons and the molecules of the samples are elastic (Rayleigh scattering) and hence their energies are not changed. They produce a strong band in the spectrum at $\Delta v=0 \mathrm{~cm}^{-1}$, corresponding to the excitation wavelength, and is removed by filters. The dipole moment that is induced by the electric field oscillates at the same frequency as the passing electromagnetic wave, so that the molecule acts as a source, sending out radiation of that frequency in all directions. As the electromagnetic wave passes, the polarised molecule ceases to oscillate and returns to its original ground level in a very short time (approximately $10^{-12} \mathrm{sec}$.). A small portion of the excited molecules $\left(10^{-6}\right.$ or less) may undergo a change in polarisability during one of the normal vibrational modes. This provides the basis of the Raman effect. Usually the incident radiation, $v_{0}$, is absorbed by a molecule in the lowest vibrational state. If 
the molecule re-emits by returning, not to the original vibrational state, but to an excited vibrational level, $v_{1}$, the emitted radiation is of lower frequency $\left(v_{0}-v_{1}\right)$ than the incident radiation. The difference in frequency is equal to a natural vibration frequency of the molecule's ground electronic state. The lines connected with these shifts are called Stokes lines and correspond to different vibrations in the molecule. A few of the molecules will initially absorb radiation while they are in an excited vibrational state and will decay to a lower energy level, so that their Raman scattered light will have a higher frequency than the incident radiation. The lines connected with these lines are called antiStokes lines. These lines are not as strong as the Stokes lines since fewer molecules are in an excited stage, according to the Boltzmann distribution $[14,15]$.

\section{Detectors and Lasers in Raman}

One reason that Raman spectroscopy hasn't been widely accepted is the problems with coloured samples and fluorescence. These problems are connected with the use of visible lasers since coloured samples absorb the source radiation and even very weak fluorescence is much stronger than the Raman scatter. These problems have by large been overcome by the development of near infrared (NIR) laser sources. In this investigation a Nd:YAG (Neodymium : Ytrrium Aluminium Garnet) laser emitting at $1064 \mu \mathrm{m}$ has been used. However, two other problems arise with the $1064 \mu \mathrm{m}$ laser namely that of iron-containing samples and that of loss in the Raman intensity. Iron has an electronic transition corresponding to that wavelength and the radiation will be consumed by the iron leaving only noise in the spectrum. Raman scattering intensity is inversely proportional to the forth power of the laser wavelength [16]. Thus one will loose significantly in Raman intensity by using long-wave lasers. 
There are two detectors in common use with NIR FT-Raman instrumentation: Germanium $(\mathrm{Ge})$ and Indium Gallium Arsenide (InGaAs). In this study an InGaAs detector was used. It is sensitive in the near infrared and may be used at either room temperature or at liquid nitrogen temperature $(77 \mathrm{~K})$. At liquid nitrogen temperature the sensitivity of the detector is improved and the inherent detector noise reduced; however, the working range of the detector is also reduced from $3600 \mathrm{~cm}^{-1}$ below the laser wavenumber to $3000 \mathrm{~cm}^{-1}$ below [17].

\section{Surface Reactions}

\section{Acidic and alkaline sites at the ZnS surface}

The understanding of surface complexation (sorption) at the oxide/water interface has been greatly developed during the past decades [18-20]. This understanding has recently been extended to sulphide minerals [2123]. Rönngren et al. have proposed a surface complexation model for $\mathrm{ZnS}$, which revealed the ion exchange and acid-base properties of hydrous $\mathrm{ZnS}$ [22]. The $\mathrm{ZnS}$ surface will contain both $\mathrm{OH}$ and $\mathrm{SH}$ groups that are formed in a dissociativ adsorption of water:

$$
\begin{aligned}
& \equiv \mathrm{SZn}-\mathrm{H}_{2} \mathrm{O} \rightarrow \quad \rightarrow \mathrm{SZnOH} \\
& \equiv \mathrm{ZnS} \quad \equiv \mathrm{ZnSH}
\end{aligned}
$$

Depending on $\mathrm{pH}$, the surface groups can undergo various hydrolysis reactions:

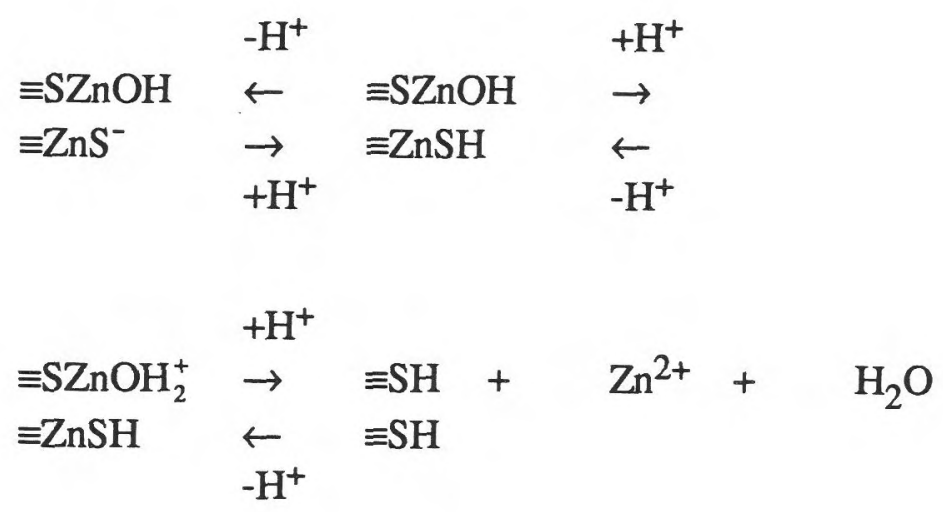


So, at low $\mathrm{pH}$ the dominating surface species will be $\equiv \mathrm{SH}$ which changes to $\equiv \mathrm{SZnOH}$ at high $\mathrm{pH}$. There is also an ion exchange $\mathrm{Zn}^{2+} / \mathrm{H}^{+}$ at low $\mathrm{pH}$. If air gets in contact with the $\mathrm{ZnS}$, the alkaline site may change to $\equiv \mathrm{SZnOHCO}_{2}[24]$ :

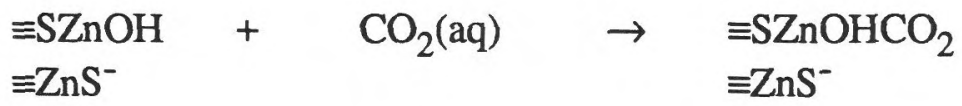

\section{Sorption of Xanthate}

IR studies of xanthate at the surface of sulphide minerals, pioneered by Little and Leja [25], Little et al. [26,27], Leja et al. [28] and Poling and Leja [29], has been the subject of many investigations. Great contribution on the understanding of the interaction between galena and potassium amylxanthate in relation to flotation has been made by De Donato et al. [30], Cases et al. [31,32], Kongolo et al. [33] and Cases and De Donato [34] and of the interaction of amylxanthate with pyrite by Cases et al. [35,36]. Due to the works by Ray et al. [37], Mattes and Pauleickhoff [38,39] and Colthup and Porter Powell [40] the vibrational modes of xanthates have been largely understood. However, still new progress is being made, most recently by Persson [41], Ihs $e t$ al. [42] and Woods et al.[43] who have detected chemisorbed xanthate at sulphide, gold electrode, and metal surfaces respectively.

\section{RESEARCH OBJECTIVE AND SCOPE}

The aim of the present work has been to use FT-IR and FT-Raman measurements to obtain information about the identity and bonding structure of the surface complexes in sulphide minerals. $\mathrm{ZnS}$ was chosen because it is a IR-transmitting material and therefore well suited for spectroscopic studies. Since it is also a white substance it is not expected to cause any troubles in the Raman measurements. The study also aimed to throw light on the mechanism of sorption of amyl xanthate 
on $\mathrm{ZnS}$. Even though earlier studies, concerning surface complexation of sulphide minerals, have been performed using other methods, this study is urgent since it can provide more direct evidence than can be obtained from, e.g., potentiometric titrations.

\section{EXPERIMENTAL}

\section{Material}

Colloidal $\mathrm{ZnS}$ was prepared by adding $100 \mathrm{mM} \mathrm{Na}_{2} \mathrm{~S}$ solution to a 100 $\mathrm{mM} \mathrm{Zn}\left(\mathrm{NO}_{3}\right)_{2}$ solution. The amounts were chosen to obtain either a precipitate with an excess of zinc ions, an excess of sulphide ions or a stoichiometric composition of the two ions. To obtain a stoichiometric mixture, sulphide solution was added until a $\mathrm{pH}$ of 8.6 was reached. According to Persson et al. [44], powder X-ray diffraction measurements show that the very same crystalline phase is obtained independent of the stoichiometry at the preparation. The specific surface area of the precipitated zinc sulphide was measured by the BET method [45] and amounted to $115.0 \mathrm{~m}^{2} / \mathrm{g}$, based on two measurements.

The potassium amyl xanthate (KAX) was provided by Hoechst and proved to be $100 \%$ pure when tested spectrophotometrically at $301 \mathrm{~nm}$ for the $\varepsilon$-value.

The $\mathrm{pH}$-values were adjusted with dilute $\mathrm{HClO}_{4}$ and $\mathrm{NaOH}$ solutions and these chemicals were reagent pure.

\section{Methods}

In order to identify the Brönsted acidic and alkaline sites at the $\mathrm{ZnS} /$ water interface, three sets of experiments were performed, each with different stoichiometry of synthetic zinc sulphide. The suspensions were stirred with a magnetic stirrer for 18 hours. Then the samples were vacuumfiltrated $(0.2 \mu \mathrm{m})$ and rinsed with deionized water several times. $50 \mathrm{~cm}^{3} 0.1 \mathrm{M} \mathrm{NaClO}_{4}$ medium solution was added to the filtered samples in order to keep the ionic strength constant and to 
imitate the conditions used in the corresponding titrations. After adjusting the $\mathrm{pH}$, the samples were stirred at $25^{\circ} \mathrm{C}$ for another $18 \mathrm{~h}$ to attain equilibrium. The $\mathrm{pH}$ was once again recorded and the suspensions were refiltered and rinsed several times with deionized water. Finally, the precipitates were dried in an evacuated desiccator for $12 \mathrm{~h}$ and the spectra were recorded.

For the sorption study of amylxanthate ions on $\mathrm{ZnS}$, four sets of experiments were performed, each with different total concentration of $\operatorname{KAX}(0.1,1,10$ and $100 \mathrm{mM})$.

Stoichiometric $\mathrm{ZnS}$ precipitates were vacuum filtered $(0.2 \mu \mathrm{m})$ and rinsed several times with deionized water. $40 \mathrm{ml}$ of $\mathrm{KAX}$, that also were $0.10 \mathrm{M}$ in $\mathrm{NaClO}_{4}$, was added to the precipitates. The pH's were adjusted and the suspensions were stirred for $18 \mathrm{~h}$. Then $\mathrm{pH}$ was measured, the suspensions rinsed with $40 \mathrm{ml}$ of destilled water, filtered and dried for $18 \mathrm{~h}$. Finally the FT-IR and FT-Raman spectra of the samples were recorded.

A reference sample was made by adding $40 \mathrm{ml} 0.065 \mathrm{M} \mathrm{Zn}\left(\mathrm{NO}_{3}\right)_{2}$ solution and $0.8 \mathrm{~g} \mathrm{KAX}$ to $1.0 \mathrm{~g}$ of $\mathrm{ZnS}$, filtering the suspension and finally drying the solid phase in a desiccator.

\section{Instrumentation}

FT-IR: Perkin-Elmer FT-IR $1760 \mathrm{X}$ spectrometer.

FT-Raman: Perkin-Elmer NIR FT-Raman $1700 \mathrm{X}$ spectrometer.

UV/VIS: Perkin-Elmer Lambda 2S UV/VIS spectrometer.

BET: Micromeretics ASAP 2000.

\section{FT-IR Measurements (DRIFT)}

Samples of $5 \% \mathrm{ZnS}$ mixed with $\mathrm{KBr}$ were placed in a small container, where they were struck by source radiation which they diffusely reflected in various directions. This radiation was measured with a TGS 
detector against a reference spectrum of pure powdered $\mathrm{KBr}$. Typically 32 scans were accumulated at $4 \mathrm{~cm}^{-1}$ resolution.

\section{FT-Raman Measurements}

The samples were excited with $100 \mathrm{~mW}$ of unpolarised, intensitystabilised $(0.1 \% \mathrm{rms}) 1064 \mathrm{~nm}$ radiation from a Spectron SL 301 series Nd:YAG laser, and the scattered light collected with $180^{\circ}$ backscattering geometry optics. The InGaAs detector and integral preamplifier were cooled to $77 \mathrm{~K}$ (liquid nitrogen) as this yields a fourfold gain in signal-to-noise performance. The interference filters used to reject light at the excitation wavelength allowed collection of scattered light with a Raman shift greater than $-200 \mathrm{~cm}^{-1}$. The mirror drive speed was $0.1 \mathrm{~cm} / \mathrm{s}$ and 100 scans were accumulated at $4 \mathrm{~cm}^{-1}$ resolution. The Raman spectra presented in this paper have been corrected for instrumental response as a function of wavelength. This was done primarily to avoid gross misinterpretation of relative peak heights. The correlation method used was that of Petty et al. [46]. The emission source in this procedure was an electric tube furnace loaded with crushed ceramics, at a temperature of $1373 \pm 5 \mathrm{~K}$ (integral thermocouple rated at $1550 \mathrm{~K}$ ).

\section{BET Measurements}

The method of Braunauer et al.[45] was used.

\section{UV/Vis Measurements}

$0.1 \mathrm{~g}$ of $\mathrm{ZnS}$ was added to flasks containing $30 \mathrm{ml}$ of $5 \mathrm{mM}$ potassium amylxanthate, each with a different $\mathrm{pH}$. After 60 minutes the residual xanthate concentration was measured spectrophotometrically at $301 \mathrm{~nm}$. 


\section{RESULTS AND DISCUSSION}

The formed surface species are not expected to amount to more than one monolayer, so therefore the absorption bands originating from them are expected to be weak compared to the ones from the bulk. However, if the particles are small, the increased surface to volume ratio will allow identification of the surface species.

\section{Acidic and Alkaline Sites at the ZnS/water Interface (paper I)}

The ZnS surface can undergo different reactions depending on stoichiometry and $\mathrm{pH}$. If the surface is stoichiometric and the sample is in contact with air, both acidic and alkaline sites will be present, depending on the $\mathrm{pH}$ :

$$
\begin{aligned}
& \equiv \mathrm{Zn}+\mathrm{H}_{2} \mathrm{O}+\mathrm{CO}_{2} \rightarrow \quad \\
& \equiv \mathrm{S}
\end{aligned}
$$

This $\mathrm{pH}$ dependence is clearly demonstrated in Fig. 6. If the $\mathrm{pH}$ is low, more $\equiv \mathrm{SH}$, indicated by the stronger band around $2500 \mathrm{~cm}^{-1}$, will be formed through an ion exchange reaction:

$\equiv \mathrm{ZnSH}+2 \mathrm{H}^{+} \rightarrow \quad \equiv \mathrm{ZnSH}+\mathrm{H}_{2} \mathrm{O}+\mathrm{CO}_{2}+\mathrm{Zn}^{2+}$ $\equiv \mathrm{SZnOHCO}_{2} \quad \equiv \mathrm{SH}$

At high $\mathrm{pH} \equiv \mathrm{ZnOHCO}_{2}$, indicated by the bands aaround 1475 and $1375 \mathrm{~cm}^{-1}$, is formed.

The bands at $1100-1000 \mathrm{~cm}^{-1}$ and 630 are due to unidentified oxidation products of sulphur.

If the surfaces exhibits excess of sulphide ions, $\equiv \mathrm{SH}$ can be identified at all $\mathrm{pH}$ 's (the $2500 \mathrm{~cm}^{-1}$ band becomes more pronounced when the $\mathrm{pH}$ is low) but $\equiv \mathrm{ZnOHCO}_{2}$ can be identified only in spectra of the most alkaline samples (Figs 7,8). The alkaline site is produced through an ion exchange reaction $\mathrm{OH}^{-} / \mathrm{HS}^{-}$and a subsequent adsorption of $\mathrm{CO}_{2}$ : 


$$
\begin{aligned}
& \equiv \mathrm{ZnSH}+\mathrm{OH}^{-}+\mathrm{CO}_{2} \rightarrow \begin{array}{l}
\equiv \mathrm{ZnOHCO}_{2}+\mathrm{HS}^{-} \\
\equiv \mathrm{S}
\end{array} \\
& \equiv \mathrm{S}
\end{aligned}
$$

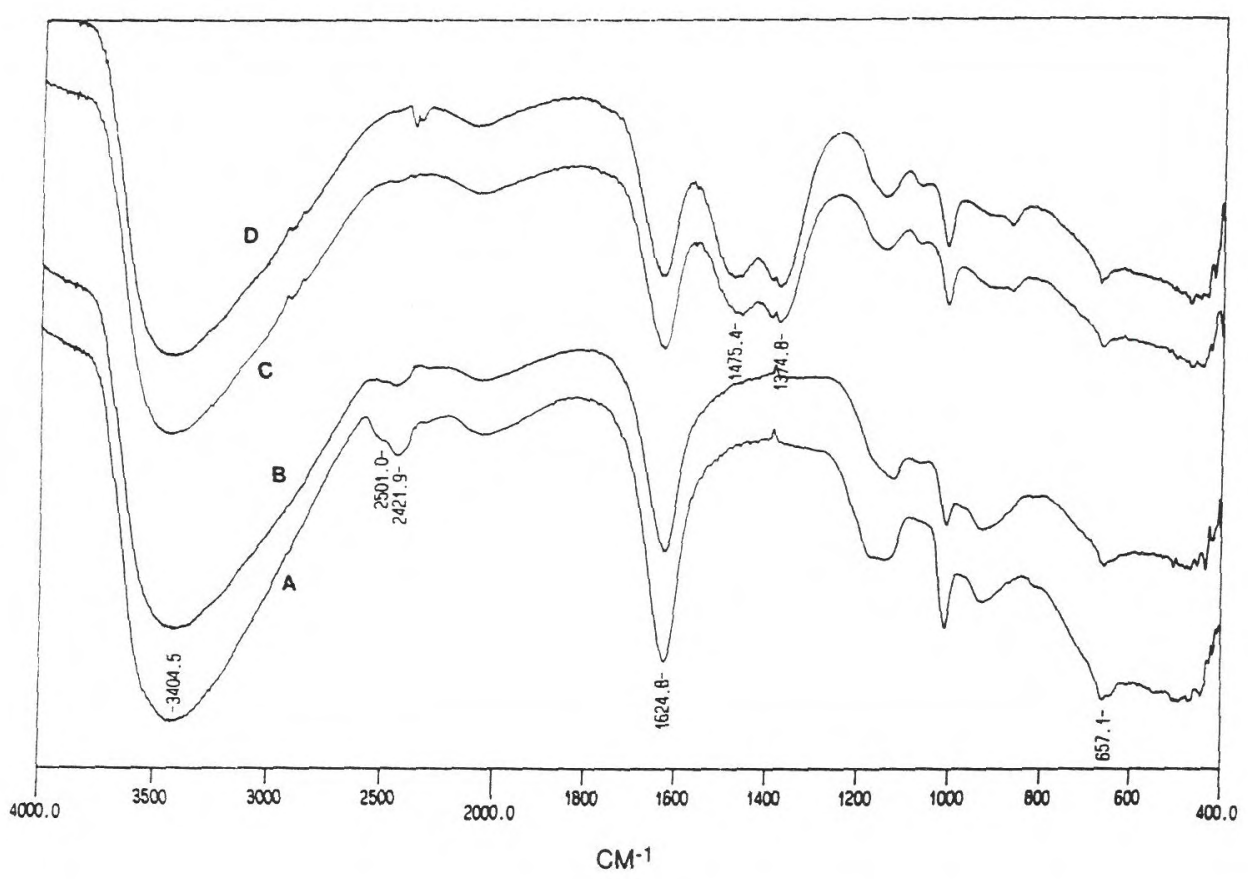

Fig. 6. FT-IR spectra of stoichiometric samples. $p H$ values: $A=4.2$;

$$
B=7.2 ; C=11.0 ; D=11.8
$$

When the surface is covered with sulphide ions, it is protected from oxidation, at least in alkaline solution. In the most acidic solutions $\mathrm{H}^{+}$ will react with $\mathrm{S}^{2-}$ to produce $\mathrm{H}_{2} \mathrm{~S}(\mathrm{~g})$ and since the redox level is raised thereby, some of the SH groups will be oxidised:

$$
\begin{array}{ll}
\equiv \mathrm{SH}+(\mathrm{O}) \rightarrow & \equiv \mathrm{SH} \\
\equiv \mathrm{ZnSH} & \\
& \equiv \mathrm{ZnS}_{\mathrm{x}} \mathrm{O}_{\mathrm{y}}
\end{array}
$$




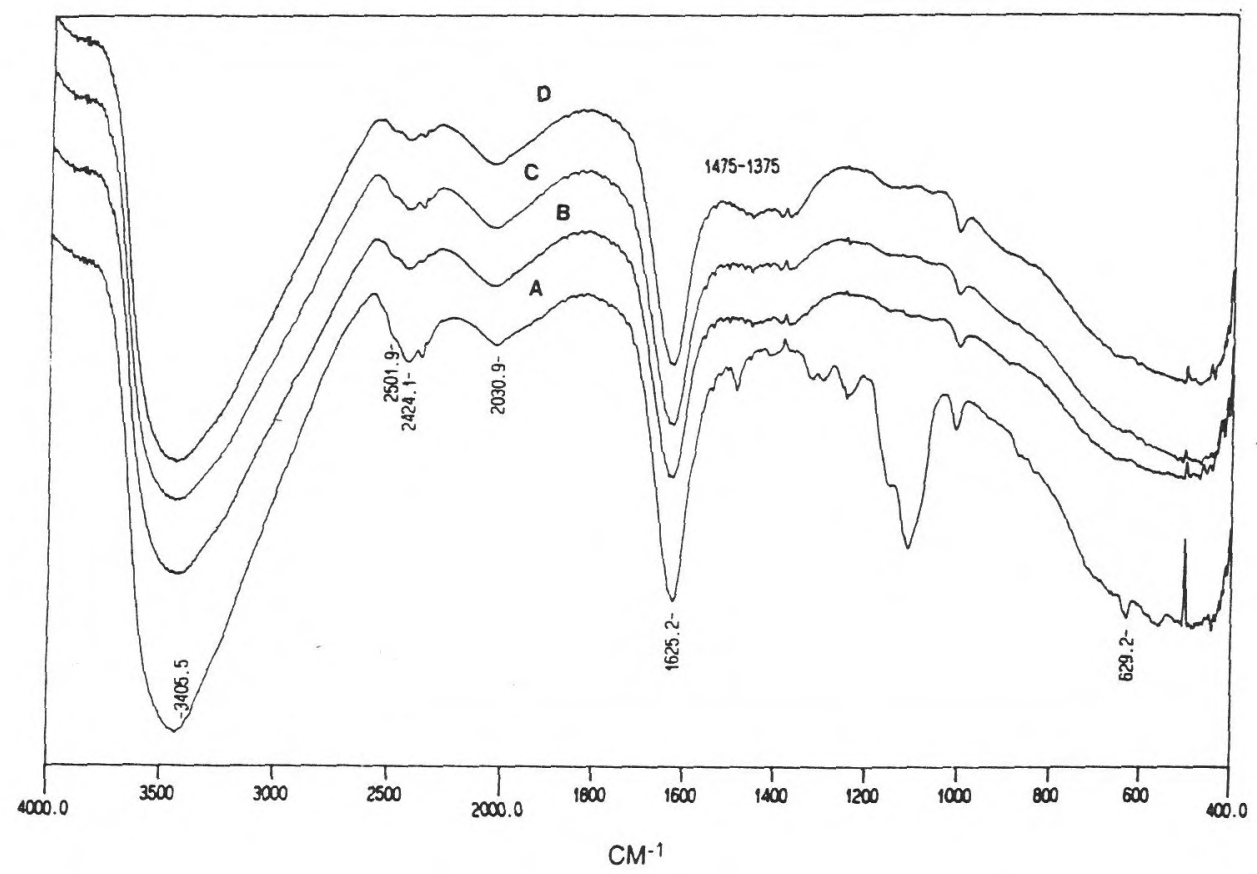

Fig. 7. FT-IR spectra of samples made with excess $S^{2-}$. $p H$ values:

$$
A=2.7 ; B=9.2 ; C=9.8 ; D=10.2
$$

If the samples are made with an excess of $\mathrm{Zn}^{2+}$, the absorption bands from the $\mathrm{ZnOHCO}_{2}$ entity is present in the spectra of the most alkaline samples (Fig 9):

$$
\begin{aligned}
& \equiv \mathrm{SZn}^{+}+\mathrm{OH}^{-}+2 \mathrm{CO}_{2} \rightarrow \equiv \mathrm{SZnOHCO}_{2} \\
& \equiv \mathrm{ZnOH} \quad \equiv \mathrm{ZnOHCO}_{2}
\end{aligned}
$$

Due to the cover of $\mathrm{Zn}^{2+}$ ions at the surface very small amounts of SH groups are formed and they are also easily oxidised because the $\mathrm{Zn}^{2+}$ ions in solution will raise the redox level. 


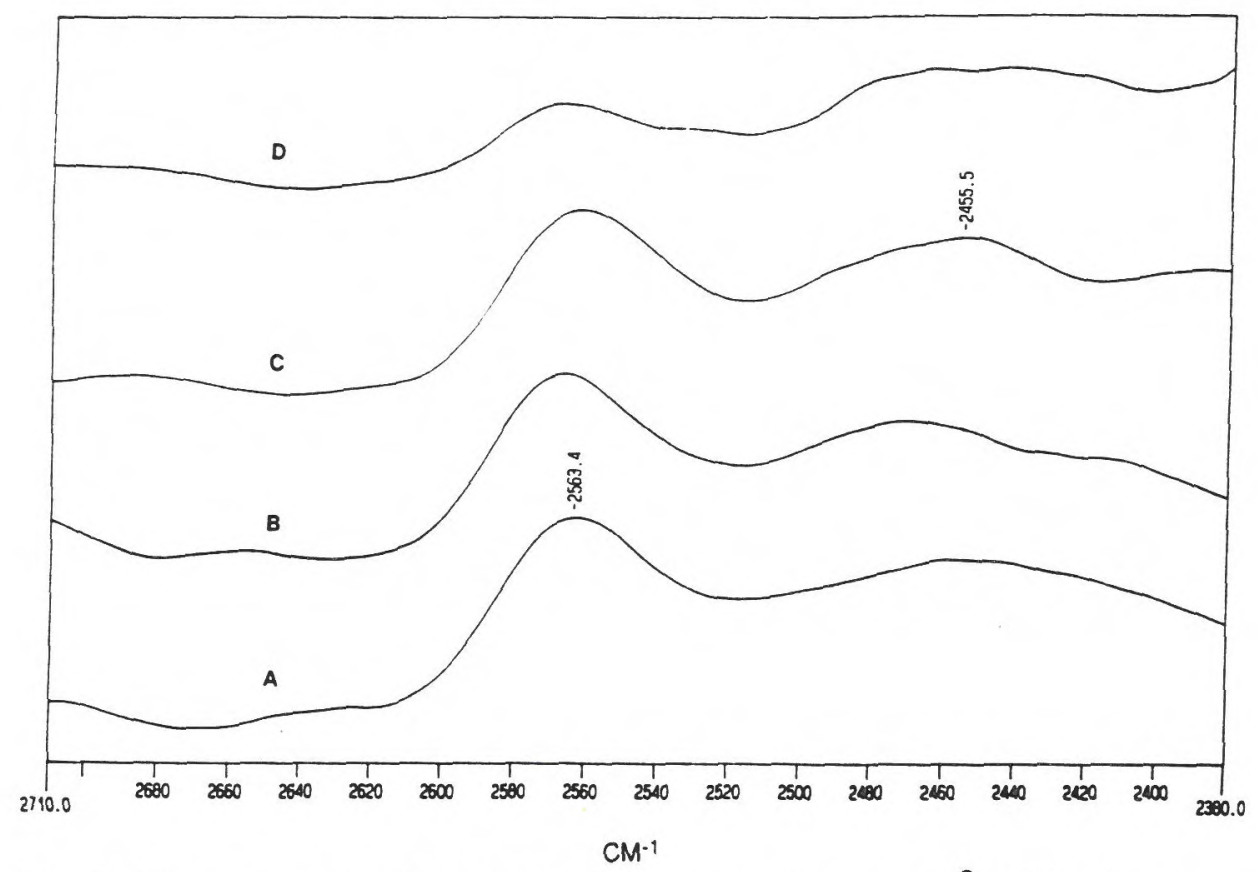

Fig. 8. FT-Raman spectra of samples made with excess $S^{2-} p H$ values:

$A=2.7 ; B=9.2 ; C=9.8 ; D=10.2$

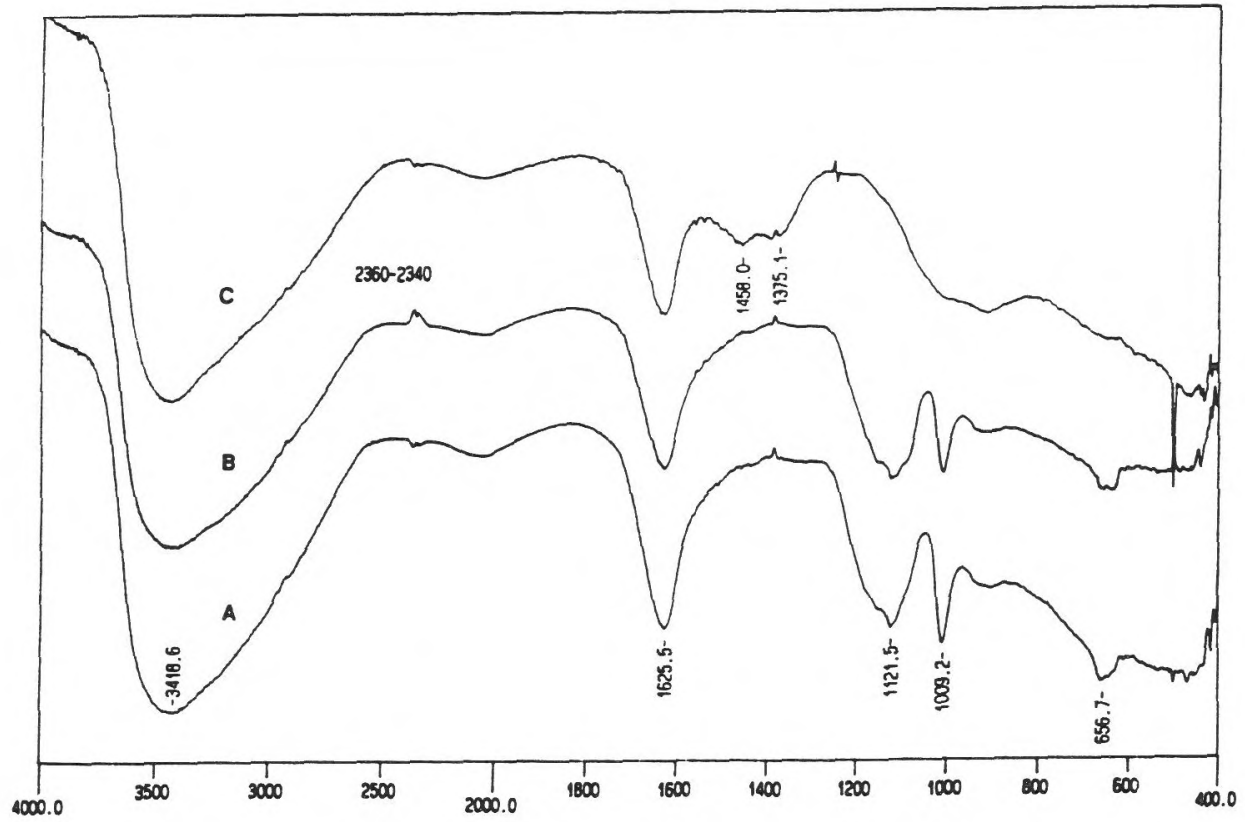

$\mathrm{CM}^{-1}$

Fig. 9. FT-IR spectra of samples made with excess of $\mathrm{Zn}^{2+}$. $\mathrm{pH}$ values: $A=4.0 ; B=4.5 ; C=8.8$ 
Sorption of amylxanthate ions (paper II)

The absorption bands are often highly coupled [40,47,41] and therefore it is not always possible to assign them to one specific vibration. In table 1 the vibrations, that give the greatest contributions to the absorption bands, are presented.

\section{Table 1}

Assignment of Absorption bands (Wavenumbers in $\mathrm{cm}^{-1}$ )

$\begin{array}{clc}1045 & v_{\mathrm{a}}\left(\mathrm{CS}_{2}\right) & 27,40,47 \\ 1133 & v(\mathrm{COC}) & 27,40 \\ 1204 & v(\mathrm{COC}) & 27,40 \\ 1370-1460 & \equiv \mathrm{ZnOHCO}_{2} & 24 \\ 1379 & \delta_{\mathrm{s}}\left(\mathrm{CH}_{3}\right), \omega\left(\mathrm{CH}_{2}\right) & 40 \\ 1458 & \delta_{\mathrm{s}}\left(\mathrm{CH}_{2}\right), \delta_{\mathrm{a}}\left(\mathrm{CH}_{3}\right) & 40 \\ 1614 & \delta(\mathrm{HOH}) & 48 \\ 2093 & v_{2}\left(\mathrm{H}_{2} \mathrm{O}\right)+v_{\mathrm{R}}\left(\mathrm{H}_{2} \mathrm{O}\right) & 49 \\ 2343+2362 & v_{3}\left(\mathrm{CO}_{2}\right) & 50 \\ 2419 & v\left(\mathrm{SH}^{2}\right) & 24,51,52 \\ 2859 & v_{\mathrm{s}}\left(\mathrm{CH}_{2}\right) & 40 \\ 2871 & v_{\mathrm{s}}\left(\mathrm{CH}_{3}\right) & 40 \\ 2931 & v_{\mathrm{a}}\left(\mathrm{CH}_{2}\right) & 40 \\ 2957 & v_{\mathrm{a}}\left(\mathrm{CH}_{3}\right) & 40 \\ 3370 & v(\mathrm{OH}) & 48\end{array}$


Effect of $\left[A X^{-}\right]_{\text {tot }}$ and $\mathrm{pH}$ on the acidic site

At high $\left[\mathrm{AX}^{-}\right]_{\text {tot }}$ and a low $\mathrm{pH}$ the absorption band due to the $\mathrm{S}-\mathrm{H}$ stretch is strong (see Fig. 10).

It is of course expected that a more acidic solution will produce more $\equiv$ $\mathrm{SH}$. The effect of $\mathrm{AX}^{-}$on the acidic site can be explained by ion exchange $\mathrm{H}^{+} / \mathrm{Zn}^{2+}$. When zinc ions leave the surface to form $\mathrm{Zn}(\mathrm{AX})_{2}$ precipitate, a new sulphur site is formed which adsorbs protons:

$$
\begin{aligned}
& \equiv \mathrm{SZnOHCO}_{2}+2 \mathrm{AX}^{-}+2 \mathrm{H}^{+} \rightarrow \equiv \mathrm{SH}+\mathrm{CO}_{2}+\mathrm{H}_{2} \mathrm{O}+\mathrm{Zn}(\mathrm{AX})_{2} \\
& \equiv \mathrm{SH} \\
& \equiv \mathrm{SH}
\end{aligned}
$$

An ATR spectrum of a $50 \mathrm{mM} \mathrm{KAX}$-solution at $\mathrm{pH}=4.4$ (fig 11C) shows no sign of $\mathrm{SH}$, so that group definitely originates from the $\mathrm{ZnS}$ surface. Furthermore, amylxantic acid is reported to have a $\mathrm{pK}_{\mathrm{a}}$-value of 1.72 [53], which rules out the possibility of the $\mathrm{SH}$ group belonging to xanthic acid.

\section{Effect of $\left[\mathrm{AX}^{-}\right]_{\text {tot }}$ and $\mathrm{pH}$ on the alkaline site}

In a closed system the alkaline site will be $\equiv \mathrm{ZnOH}[21,22]$, but when the system is open to air, as in this investigation as well as in practical flotation, the alkaline site will change to $\equiv \mathrm{ZnOHCO}_{2}$ [24]. Xanthate competes with $\mathrm{HCO}_{3}^{-}$for the zinc sites:

$\equiv \mathrm{ZnOHCO}_{2}+\mathrm{AX}^{-} \rightarrow \equiv \mathrm{ZnAX}+\mathrm{HCO}_{3}^{-}$

As demonstrated in Fig. 10 the absorption bands corresponding to the alkaline site are more pronounced at high $\mathrm{pH}$ and low total KAX concentrations.

The absorption bands of the alkaline site are in about the same position as some of the vibrations in the hydrocarbon chain of the xanthate ion. However, the shape of the bands are quite different, so a distinction between them is possible to make. 


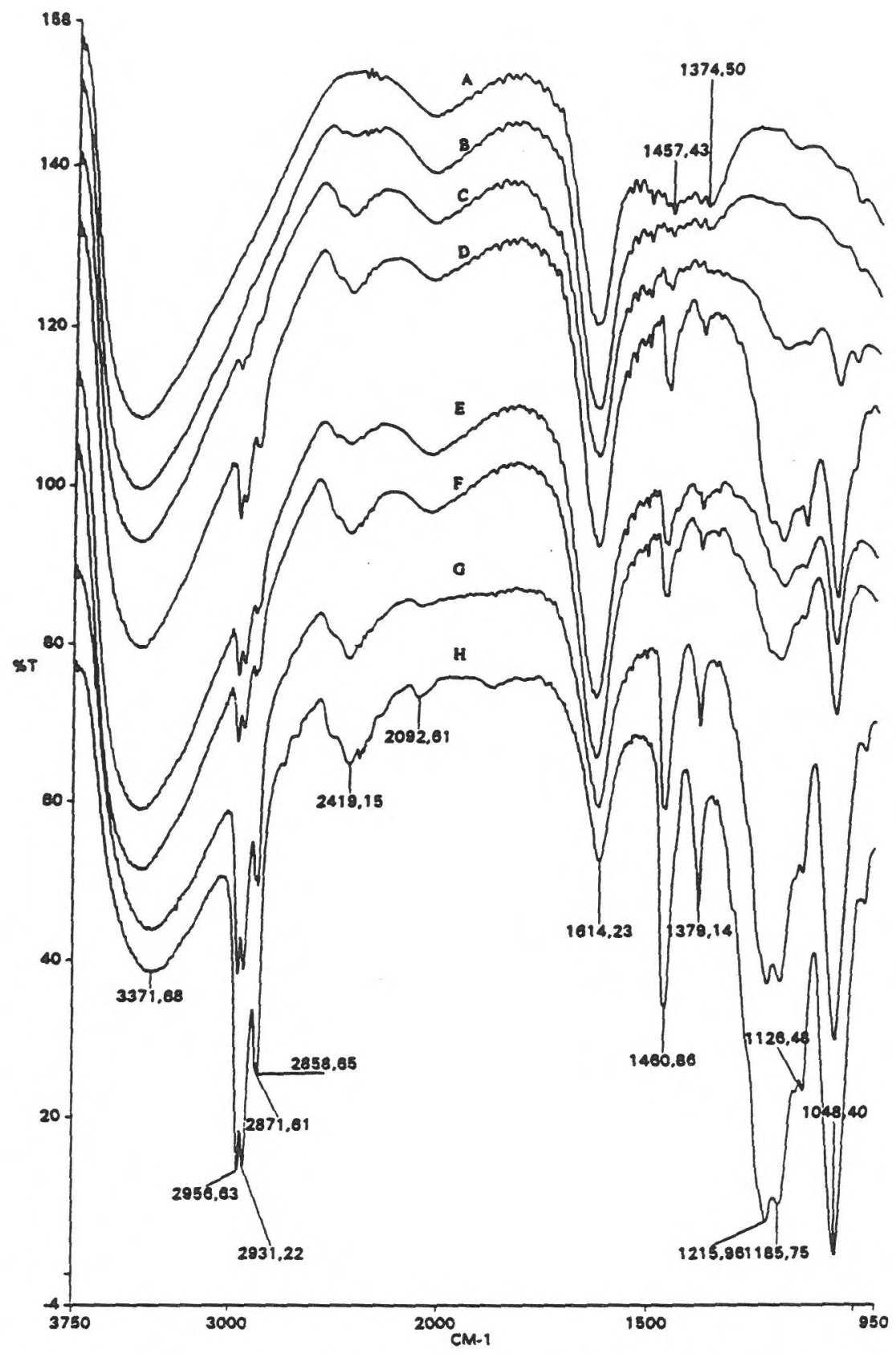

Fig. 10. FT-IR spectra of samples with varying $p H$. A-D at $10 \mathrm{mM}, E-H$ at $100 \mathrm{mM}$ total $\mathrm{KAX}$ concentration. $\mathrm{pH}$-values: $A=10.9, B=8.8, C$ $=6.3, D=5.6, E=9.8, F=8.5, G=7.3$ and $H=7.0$. The ordinate scale is identical for all spectra. 


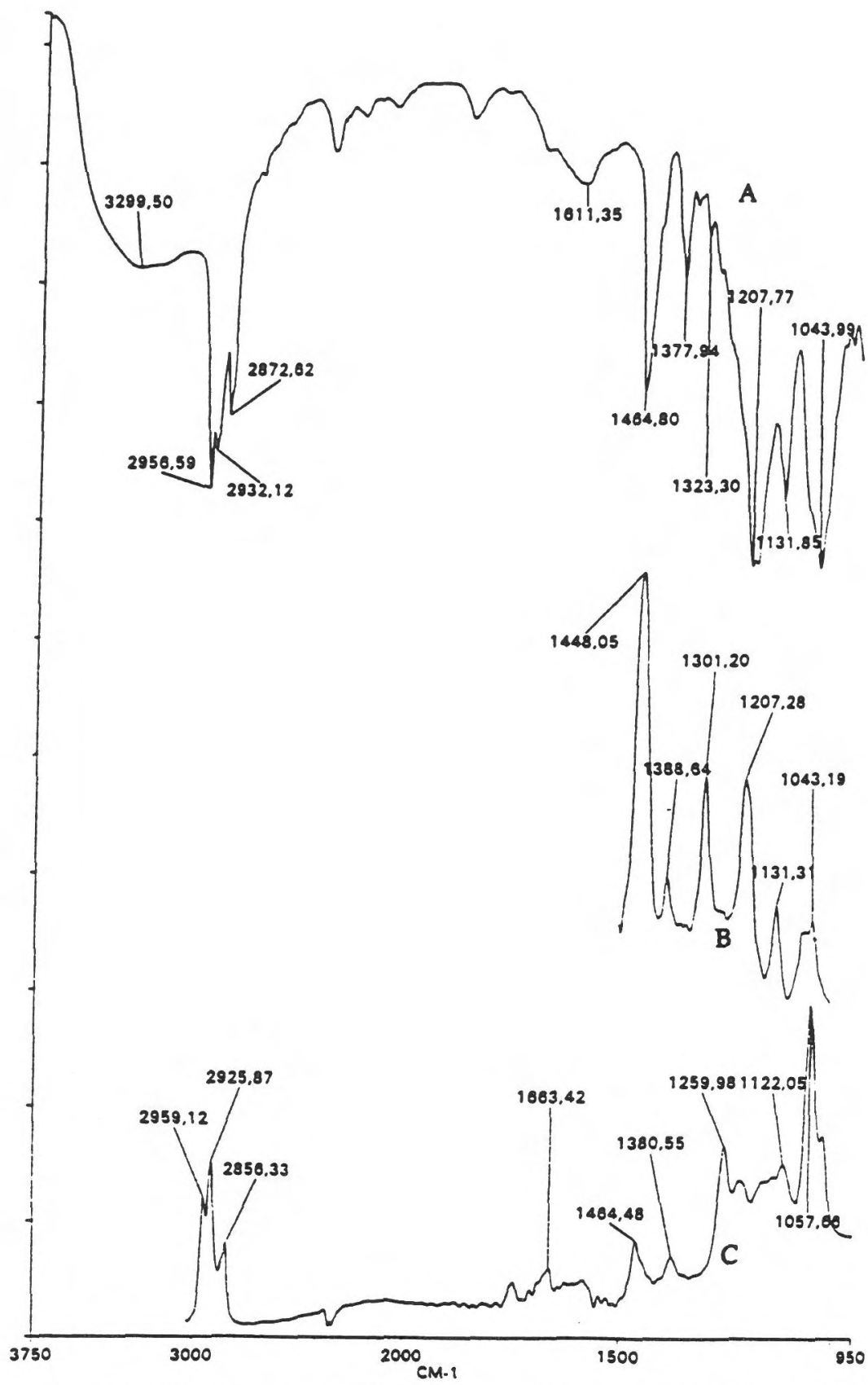

Fig. 11. FT-IR (A) and FT-Raman (B) spectra of $Z n(A X)_{2}(s)$ precipitated in the presence of $\mathrm{ZnS}(\mathrm{s}) . C=A T R$-spectrum of a $50 \mathrm{mM}$ $K A X$-solution at $p H=4.40$ soaked into a filterpaper (the spectrum of the wet filterpaper is subtracted). The ordinate scale is arbitrary. 
Effect of $p H$ and $\left[A X^{-}\right]_{\text {tot }}$ on the amount of $A X^{-}$that is sorbed As expected, more xanthate is sorbed when the initial concentration of xanthate is high (Figs. 10,12).

The higher sorption at low $\mathrm{pH}$ may have two explanations: Protons will react with the alkaline site, creating new zinc sites that can adsorb xanthate ions:

$\equiv \mathrm{ZnOHCO}_{2}+\mathrm{H}^{+} \rightarrow \equiv \mathrm{Zn}^{+}+\mathrm{CO}_{2}(\mathrm{aq})+\mathrm{H}_{2} \mathrm{O}$

and the enhanced ion exchange process $\mathrm{H}^{+} / \mathrm{Zn}^{2+}$ at low $\mathrm{pH}$ will promote precipitation of $\mathrm{Zn}(\mathrm{AX})_{2}$.

\section{Sorption Mechanism}

A comparison between the IR-spectra of the samples (Figs. 10) and the IR-spectrum of the $\mathrm{Zn}(\mathrm{AX})_{2}$ reference (Fig.11A) shows wavenumber shifts for the bands at 1044, 1132 and 1208. The corresponding Raman spectra (Figs. 12,11B) show shifts for the bands at 1043 and $1131 \mathrm{~cm}^{-1}$. Several authors consider these shifts to be an evidence for chemisorption of xanthate. However, the strong absorption bands can not be due to one monolayer. Most probably precipitation is also involved. The monolayer capacity of $\mathrm{ZnS}$ with a surface area of 115 $\mathrm{m}^{2} / \mathrm{g}$ can be estimated to $0.66 \mathrm{mmoles} / \mathrm{g}$ while the sorption capacity is about $1.5 \mathrm{mmoles} / \mathrm{g}$ (see paper II for details). This indicates that xanthate is either adsorbed in a second layer or more likely precipitated. A calculation using the SOLGASWATER program also shows that precipitation takes place at slightly alkaline to acidic conditions. 


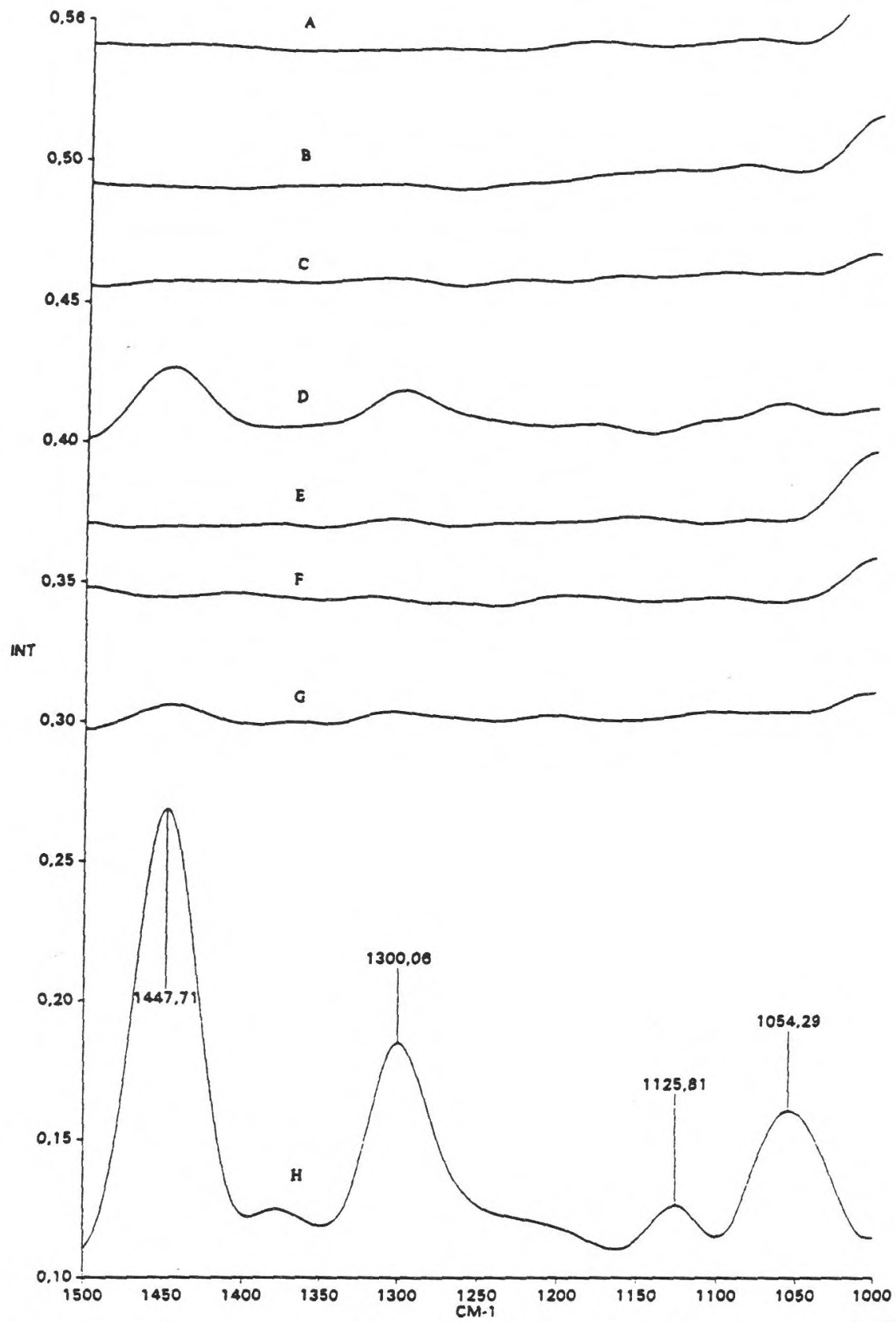

Fig. 12. FT-Raman spectra of samples with varying total KAX concentration. $A-D$ at $p H=9.66 \pm 0.15$. $E-H$ at $p H=6.65 \pm 0.35$. $K A X$ concentrations: $A=0.1 \mathrm{mM}, B=1.0 \mathrm{mM}, C=10.0 \mathrm{mM}, D=$ $100 \mathrm{mM}, E=0.1 \mathrm{mM}, F=1.0 \mathrm{mM}, G=10.0 \mathrm{mM}$ and $H=100 \mathrm{mM}$. The ordinate scale is identical for all spectra. 


\section{CONCLUSIONS AND FUTURE PLANS}

In colloidal zinc sulphide, the acidic site is $\equiv \mathrm{SH}$. The alkaline site can be denoted $\equiv \mathrm{ZnOHCO}_{2}$, provided the sample is in contact with air.

More amyl xanthate is sorbed at low $\mathrm{pH}$ and high initial xanthate concentrations. The sorption of xanthate occurs via two mechanisms: adsorption where the xanthate ion competes with $\mathrm{HCO}_{3}^{-}$and precipitation of $\mathrm{Zn}(\mathrm{AX})_{2}$ which are both favoured by low $\mathrm{pH}$.

More $\mathrm{SH}$ groups are present when $\mathrm{Zn}(\mathrm{AX})_{2}$ is precipitated, because more sulphide sites are produced through the ion exchange $\mathrm{Zn}^{2+} / \mathrm{H}^{+}$. The next project will be to investigate the mechanism for adsorption of depressors like cyanide ions and dextrin at zinc sulphide surfaces and how they affect the acidic and alkaline sites of the mineral.

\section{ACKNOWLEDGEMENTS}

First of all I wish to thank professor Willis Forsling for being my supervisor, inspirator and critic during this work.

Dr Zhong-Xi Sun, without whom none of this work would have been possible, is greatfully acknowledged for his continous support, encouragement, bold ideas, humour, deep knowledge and unsurpassed optimism.

Thanks to Dr Allan Holmgren who has given me insight into the world of vibrations.

Thank you Jonas Hedlund for making the BET measurements.

Dr Elena Babouchkina is acknowledged for making the adsorption test and Milan Vnuk for drawing the isotherm.

Dr Per Persson has made valuable comments on my interpretation of spectra and I thank him for that. 


\section{References}

1. Sherman, D.M., in "Spectroscopic Characterization of Minerals and Their Surfaces" (L.M. Coyne, S.W.S. McKeever and D.F. Blake, Eds.), p. 284-309. American Chemical Society, Washington, DC, 1990.

2. Kostov, I., "Mineralogy", p. 145. Oliver and Boyd Ltd, Edinburgh, Great Britain, 1968.

3. Mason, B. and Berry, L.G., "Elements of Mineralogy", p. 233. W.H. Freeman and Company, San Francisco, USA, 1968.

4. Jones, M.H. and Woodcock, J.T., in "Principles of Mineral Flotation" (M.H. Jones and J.T. Woodcock, Eds.), p. 147-183. The Australasian Institute of Mining and Metallurgy, Parkville, Australia, 1984.

5. Lovell, V.M., in "Principles of Flotation" (R.P. King, Ed.), p. 74. South African Institute of Mining and Metallurgy, Johannesburg, South Africa, 1982.

6. Schrader, B. in "Practical Fourier Transform Infrared Spectroscopy" (J.R. Ferraro and K: Krishnan, Eds.), p. 168. Academic Press Inc., San Diego, USA, 1990.

7. Urban, M.W. and Koenig, J.L., in "Applications of FTIR Spectroscopy" (J.R. Durig, Ed.), p. 129-132. Elsevier Science Publishers B.V., Amsterdam, The Netherlands, 1990.

8. Colthup, N.B., Daly, L.H. and Wiberly, S.E., "Introduction to Infrared and Raman Spectroscopy", p. 77. Academic Press Inc., San Diego, USA, 1990. 
9. Griffiths, P.R., in "Laboratory Methods in Vibrational Spectroscopy" (H.A Willis, J.H. van der Maas and R.G.J. Miller, Eds.) p. 132. John Wiley \& Sons Ltd., New York, USA, 1991.

10. Diem, M., "Introduction to Modern Vibrational Spectroscopy", p. 159. John Wiley \& Sons, New York, USA, 1993.

11. Colthup, N.B., in "Encyclopedia of Physical SCience and Technology", (R.A. Meyers, Ed.) p. 639. Academic Press Inc., Orlando, USA, 1987.

12. Porro, T.J. and Pattacini, S.C., Appl. Spectrosc. 44, 1170-1175 (1990).

13. Strauch, B., "Instrumentation in Analytical Chemistry, vol. 2", p. 232. Ellis Horwood Ltd, Chichester, England, 1994.

14. Colthup, N.B., Daly, L.H. and Wiberly, S.E., "Introduction to Infrared and Raman Spectroscopy", p. 60-65. Academic Press Inc., San Diego, USA, 1990.

15. Willard, H.H., Merrit, L.L.Jr., Dean, J.A. and Settle, F.A.Jr. "Instrumental Methods of Analysis", p. 217-221. D. Van Nostrand Co., New York, USA, 1981.

16. Diem, M., "Introduction to Modern Vibrarional Spectroscopy", p. 110. John Wiley \& Sons, New York, 1993.

17. Deely, C.M., "An Introduction to NIR FT-Raman Spectrometry", p.

3. Perkin Elmer, Beaconsfield, England, 1992. 
18. Shindler, P.W. and Kamber, H.R., Helv. Chim. Acta 51, 1781 (1968).

19. Shindler, P.W. and Gamsjäger, H., Kolloid Z.Z. Polym. 250, 759 (1972).

20. Stumm, W., Huang, C.P. and Jinkens, S.R., Croat. Chem. Acta. 42 , 223 (1970).

21. Sun, Z.X., Forsling, W., Rönngren, L. and Sjöberg, S., Int J. Miner. Process. 33, 83 (1991).

22. Rönngren, L., Sjöberg, S., Sun, Z., Forsling, W. and Schindler, P.W., J. Colloid Interface Sci. 145, 396 (1991).

23. Sun, Z.X., Forsling, W., Rönngren, L., Sjöberg, S. and Schibdler, P.W., Colloids Surf. 59, 243 (1991).

24. Gärd, R., Sun Z.X. and Forsling, W., J. Colloid Interface Sci. 169, 393 (1995).

25. Little, L.H. and Leja, J., Proc. 2nd Int. Congr. Surface Activity. Vol III, p. 261-266. Butterworths, London (1957).

26. Little, L.H., Poling, G.W. and Leja, J., Can. J. Chem. 39, 745 (1961).

27. Little, L.H., Poling, G.W. and Leja, J., Can. J. Chem. 39, 1783 (1961). 
28. Leja, J., Little, L.H. and Poling, G.W., Trans. I.M.M., 72, 407-423 (1963).

29. Poling, G.W. and Leja, J., J. Phys. Chem. 67, 2121 (1963).

30. De Donato, P., Cases, J.M., Kongolo, M., Michot, L. and Burneau, A., Colloids Surfaces 44, 207 (1990).

31. Cases, J.M., Kongolo, M., De Donato, P., Michot, L. and Erre, R., Int. J. Miner. Process. 28, 313 (1990).

32. Cases, J.M., Kongolo, M., De Donato, P., Michot, L. and Erre, R., Int. J. Miner. Process. 30, 35 (1990).

33. Kongolo, M., Cases, J.M., De Donato, P., Michot, L. and Erre, R., Int. J. Miner. Process. 30, 195 (1990).

34. Cases, J.M. and De Donato, P., Int. J. Miner. Process., 33, 49 (1991).

35. Cases, J.M., De Donato, P., Kongolo, M. and Michot, L., Colloids Surfaces 36, 323 (1989).

36. Cases, J.M., De Donato, P., Kongolo, M. and Michot, L., 3rd International Symposium on Beneficiation and Agglomeration, Bhubaneswar, India, 16-18 Jan. (1990).

37. Ray, A., Sathyanarayana, D.N., Prasad, G.D. and Patel, C.C., Spectrochim. Acta. 29A, 1579 (1973). 
38. Mattes, R., and Pauleickhoff, G., Spectrochim. Acta 29A, 1339 (1973).

39. Mattes, R., and Pauleickhoff, G., Spectrochim. Acta 30A, 379 (1974).

40. Colthup, N.B. and Porter Powell, L., Spectrochim. Acta. 43A, 317 (1987).

41. Persson, P., Thesis. Swedish University of Agricultural Sciences. (1990).

42.Ihs, A., Uvdal, K. and Liedberg, B., Langmuir. 9, 733-739 (1993)

43. Woods, R., Kim, D.S. and Yoon, R.-H., Colloids Surf. A: Physiochem. Eng. Aspects. 94, 67-74 (1995).

44. Persson, P., Malmensten, B. and Persson, I., J. Chem. Soc. Faraday Trans. 87, 1769 (1991).

45. Braunauer, S., Emmet, P.H. and Teller, E., Am. Chem. Soc. J. 60, 309 (1938).

46. Petty, C.J., Warnes, G.M., Hendra, P.J. and Judkins, M., Spectrochim.Acta. 47A, 1179 (1991).

47. Valli, M., Persson, P. and Persson, I., Acta Chem. Scandinavica. 48, 810 (1994).

48. Gadsden, J.A., in "Infrared spectra of minerals and related inorganic compounds", p 15, Butterworth.1975. 
49. Lutz, H.D., Pobitschka, W., Frischemeimer, B. and Becker, R.A., Appl. Spectrosc. 32, 541-547 (1978).

50. Nakamoto, K., in "Infrared and Raman spectra of inorganic and coordination compounds", p 112, John Wiley \& sons, Inc. 1986.

51. Tursi, A.J. and Nixon, E.R., J. Chem. Phys. 53, 518 (1970).

52. Acquista, N. and Schoen, L.J., J. Chem. Phys. 53, 1290 (1970).

53. Majima, H., Sci. Rep. Inst. Tohuku Univ., Series A., 13, no. 3, 183197 (1961). 
1 


\title{
FT-IR and FT-Raman Studies of Colloidal ZnS
}

\author{
1. Acidic and Alkaline Sites at the ZnS/Water Interface
}

\author{
RUNE GÄRD, ZHONG-XI SUN, AND WILLIS FORSLING' \\ Department of Inorganic Chemistry, Lulea University of Technology, S-95I 87 Luleá. Sweden
}

Received January 3, 1994; accepted July 5, 1994

\begin{abstract}
The surface complexes of colloidal $\mathrm{ZnS}$ have been studied using FT-IR and FT-Raman techniques. The absorption bands at 2500 and $1475-1375 \mathrm{~cm}^{-1}$, which are identified as the S-H bond and the $\mathrm{Zn}-\mathrm{OHCO}_{2}$ entity, respectively, can be observed under varied conditions of sample stoichiometry and $\mathrm{pH}$. The correlation between surface spectra and the complexation model is evaluated. The relation between the intensities of FT-IR and FT-Raman spectra and particle size is discussed. 1995 Academic Press, Inc.
\end{abstract}

\section{INTRODUCTION}

Aqueous metal ions and surfactants can be adsorbed onto the surfaces of various minerals, thereby changing their surface properties. Understanding of surface complexation (sorption) at the oxide/water interface has been greatly developed during the past decades $(2-4)$. This understanding has recently been extended to sulfide minerals (5-7). Sulfide minerals are normally recovered by the flotation process. In this process an organic collector is attached to the surface of the mineral. The affinity of metal sulfides for collectors is $\mathrm{pH}$-dependent. Sphalerite is a common mineral recovered by flotation. With a deeper knowledge about the processes which occur at the mineral/water interface, the activation of sphalerite by metal ions could be better understood.

Rönngren et al. have proposed a surface complexation model for $\mathrm{ZnS}$, which revealed the ion exchange and acidbase properties of hydrous zinc sulfide (6). According to this model the dominating species at the $\mathrm{ZnS}$ surface at acidic $\mathrm{pH}$ is $\equiv \mathrm{ZnSH}$, which changes to $\equiv \mathrm{ZnOH}$ at alkaline $\mathrm{pH}$. If these statements are correct, it should be possible to confirm them by FT-IR and FT-Raman spectroscopy.

Compared to traditional techniques in solution chemistry, for instance potentiometric and spectroscopic titrations, IR and Raman techniques have the advantage of being able to provide information about the identity of surface complexes and about their bonding structures. However, the surface

\footnotetext{
'To whom correspondence should be addressed.
}

monolayer species with bond lengths at the nanometer level may be difficult to detect with vibration spectroscopy, especially for opaque minerals. Nevertheless, if IR transmitting materials are used, vibration spectra of adsorbed species may be recorded. $\mathrm{ZnS}$ is a well-known IR transmitting material at wavenumbers $5000-710 \mathrm{~cm}^{-1}$ (1). The spectra of species at the $\mathrm{ZnS} /$ water interface may provide fundamental information about surface reactions. In combination with the data obtained from potentiometric titrations about surface complexation, the reaction models may be further confirmed.

Spectra of compounds containing $\mathrm{S}-\mathrm{H}$ bonds have been reported $(8-10)$. The spectra of surface $\mathrm{S}-\mathrm{H}$ and $\mathrm{Zn}-\mathrm{OH}$ bonds should resemble those in the bulk. Since the dominating species on the surface changes gradually with $\mathrm{pH}$, special attention is paid to the $\mathrm{pH}$ dependence of sample spectra. The identification of acidic and alkaline sites at the surface is the first step to confirm the surface reactions.

The particle size is also of great significance in IR and Raman measurements. The inorganic surface bond length is normally a few angstroms. If the particle size is too big, the submonolayer of adsorbed inorganics is too small in comparison and will therefore induce a very weak signal. If the particle size could be reduced to $\approx 100 \AA$, the signal from the submonolayer adsorbate would be proportionally increased. Therefore we have chosen to perform our measurements on synthetic precipitates of $\mathrm{ZnS}$ with a particle size of a few hundred angstroms.

Although this study is focused on $\mathrm{ZnS}$, it is hoped that it can throw some light on the surface complexation of other sulfide minerals.

FT-IR and FT-Raman measurements of xanthate adsorption at the surface of aqueous $\mathrm{ZnS}$ under different $\mathrm{pH}$ and stoichiometric conditions are now being performed and will be discussed in a forthcoming paper.

\section{EXPERIMENTAL}

All the chemicals in this study were reagent pure. The $\mathrm{pH}$ of the suspensions was adjusted with dilute $\mathrm{HClO}_{4}$ and $\mathrm{NaOH}$ solutions. 


\section{Sample Conditioning}

Three sets of experiments were performed, each with a different stoichiometry of synthetic zinc sulfide. $\mathrm{ZnS}$ precipitates were made by adding either equal, double, or half stoichiometric amounts of sodium sulfide $(100 \mathrm{mM})$ to $20 \mathrm{ml}$ of zinc chloride $(100 \mathrm{~m} \mathrm{M})$ in dark brown flasks with stoppers. The suspensions were stirred with a magnetic stirrer for $18 \mathrm{~h}$. The $\mathrm{pH}$ values of the suspensions were 8.6, 12.2, and 5.5 , respectively. Then the samples were vacuum filtered $(0.2 \mu \mathrm{m})$ and rinsed with deionized water several times. To the filtered samples was added $50 \mathrm{~cm}^{3} 0.1 \mathrm{M} \mathrm{NaClO}_{4}$ medium solution in order to keep the ionic strength constant and to imitate the conditions used in the corresponding titrations. After the $\mathrm{pH}$ was adjusted, the samples were stirred at $25^{\circ} \mathrm{C}$ for another $18 \mathrm{~h}$ to attain equilibrium. The $\mathrm{pH}$ was once again recorded and the suspensions were refiltered and rinsed several times with deionized water. Finally, the precipitates were dried in an evacuated desiccator for $12 \mathrm{~h}$.

In order to obtain a reference spectrum (Fig. 1) showing the $\mathrm{Zn}-\mathrm{OH}$ bending mode, zinc hydroxide was precipitated by adding a crystal of solid sodium hydroxide to $100 \mathrm{ml}$ of a $100 \mathrm{~m} M$ zinc chloride solution followed by filtration, rinsing, and vacuum-drying of the precipitate.

When $\mathrm{Zn}(\mathrm{OH})_{2}$ is precipitated, the alkalinity of the solution will enhance dissolution of carbon dioxide from the air. This will lead to formation of a mixed precipitate represented as $x \mathrm{Zn}(\mathrm{OH})_{2} \cdot y \mathrm{ZnCO}_{3}$. It is also inevitable that carbon dioxide will absorb onto the surfaces during sample preparation.

\section{Instrumentation}

A Perkin-Elmer FT-IR $1760 \mathrm{X}$ spectrometer and a Perkin-Elmer NIR FT-Raman $1700 \mathrm{X}$ spectrometer were used in this study.

\section{FT-IR Measurements (DRIFT)}

Samples of $5 \% \mathrm{ZnS}$ mixed with $\mathrm{KBr}$ were placed in a small container, where they were struck by source radiation which they diffusely reflected in various directions. This radiation was measured with a TGS detector against a reference spectrum of pure powdered $\mathrm{KBr}$. Typically 32 scans were accumulated at $4 \mathrm{~cm}^{-1}$ resolution.

\section{FT-Raman Measurements}

The samples were excited with $600 \mathrm{~mW}$ of unpolarized, intensity-stabilized $(0.1 \% \mathrm{rms}) 1064 \mathrm{~nm}$ radiation from a Spectron SL 301 Series Nd:YAG laser, and the scattered light was collected with $180^{\circ}$ backscattering geometry optics. The InGaAs detector and integral preamplifier were cooled to $77 \mathrm{~K}$ (liquid nitrogen) as this yields a fourfold gain in signal-to-noise performance. The interference filters used to reject light at the excitation wavelength allowed collection of scattered light with a Raman shift greater than $\sim 200 \mathrm{~cm}^{-1}$.

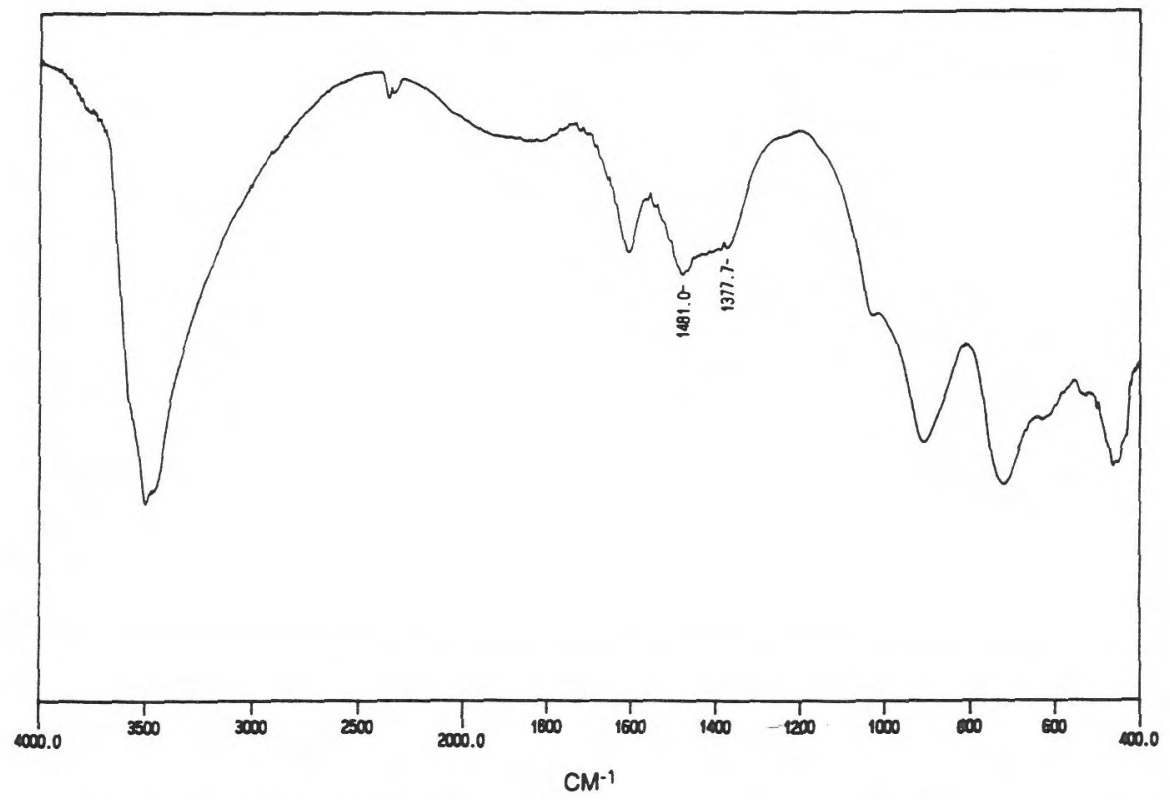

FIG. 1. FT-IR spectrum of $x \mathrm{Zn}(\mathrm{OH}) \cdot y \mathrm{ZnCO}_{3}$. The precipitate was made by adding one crystal of $\mathrm{NaOH}(\mathrm{s})$ to $100 \mathrm{ml}$ of $100 \mathrm{mM} \mathrm{ZnCl}(\mathrm{aq})$. 
TABLE 1

Assignment of Absorption Bands According to Literature and Experimental Data (Wavenumbers in $\mathrm{cm}^{-1}$ )

\begin{tabular}{|c|c|c|c|c|}
\hline \multirow[b]{2}{*}{ Vibration } & \multicolumn{2}{|c|}{ FT-IR } & \multicolumn{2}{|c|}{ FT-Raman } \\
\hline & Exp. & Ref. & Exp. & Ref. \\
\hline $\mathrm{OH}$ stretch & $3405-3419$ & $3600-3200(12)$ & & \\
\hline S-H stretch & $2501-2424$ & $\begin{array}{l}2541^{a}(10) \\
2591^{b}(10) \\
2633-2619^{a}(9)\end{array}$ & $2555-2459$ & $2554-2521(8)$ \\
\hline$\nu_{3}\left(\mathrm{CO}_{2}\right)$ & $2360-2340$ & $2349(13)$ & & \\
\hline$\nu_{\max }\left(\mathrm{H}_{2} \mathrm{O}\right)$ & 2031 & $\sim 2130(15)$ & & \\
\hline $\mathrm{HOH}$ bend & 1625 & $1650(12)$ & & \\
\hline $\mathrm{Zn}-\mathrm{OHCO}_{2}$ & $1485-1375$ & $\begin{array}{l}1481-1378 \\
\text { (this work) }\end{array}$ & & \\
\hline$\nu_{3}\left(\mathrm{SO}_{4}^{-2}\right)$ & $1122-1009$ & $1104(14)$ & & \\
\hline$v_{4}\left(\mathrm{SO}_{4}^{-2}\right)$ & $657-630$ & $630(14)$ & & \\
\hline
\end{tabular}

${ }^{a} \mathrm{H}_{2} \mathrm{~S}$ in solid nitrogen matrix.

${ }^{b} \mathrm{H}_{2} \mathrm{~S}(\mathrm{~g})$.

The mirror drive speed was $0.1 \mathrm{~cm} / \mathrm{s}$ and 100 scans were accumulated at $4 \mathrm{~cm}^{-1}$ resolution. The Raman spectra presented in this paper have been corrected for instrumental response as a function of wavelength. This was done primarily to avoid gross misinterpretation of relative peak heights. The correlation method used was that of Petty et al.
(11). The emission source in this procedure was an electric tube furnace loaded with crushed ceramics, at a temperature of $1373 \pm 5 \mathrm{~K}$ (integral thermocouple rated at $1550 \mathrm{~K}$ ).

\section{RESULTS AND DISCUSSION}

The absorption bands arising from monolayer species are expected to be very weak but due to the small particle size they appear to be strong enough to be interpreted and assigned to certain vibrations.

All the spectra have strong bands at 3400 and $1650 \mathrm{~cm}^{-1}$, due to the $\mathrm{O}-\mathrm{H}$ stretch and $\mathrm{H}-\mathrm{O}-\mathrm{H}$ bend in the water in the crystal structure. It is clear that such water exists even after $12 \mathrm{~h}$ of drying under vacuum.

The broad absorption band at $1475-1375 \mathrm{~cm}^{-1}$ originates from $\equiv \mathrm{ZnOHCO}_{2}$. This has been shown by obtaining a spectrum of a mixed precipitate, $\mathrm{xZn}(\mathrm{OH})_{2} \cdot \mathrm{yZnCO}_{3}$ (Fig. 1).

The bands at 2360 and $2340 \mathrm{~cm}^{-1}$ which appear in some spectra are due to the $\mathrm{CO}_{2}$ in the air.

The band at $2031 \mathrm{~cm}^{-1}$ is an association (combination) band of water. Lutz et al. (15) have assigned it to the transition $\nu_{2}+\nu_{R}$, where $\nu_{2}$ is the bending mode and $\nu_{R}$ is a librational mode.

Assignments of the absorption bands that occur in the spectra and their positions according to literature are listed in Table 1.

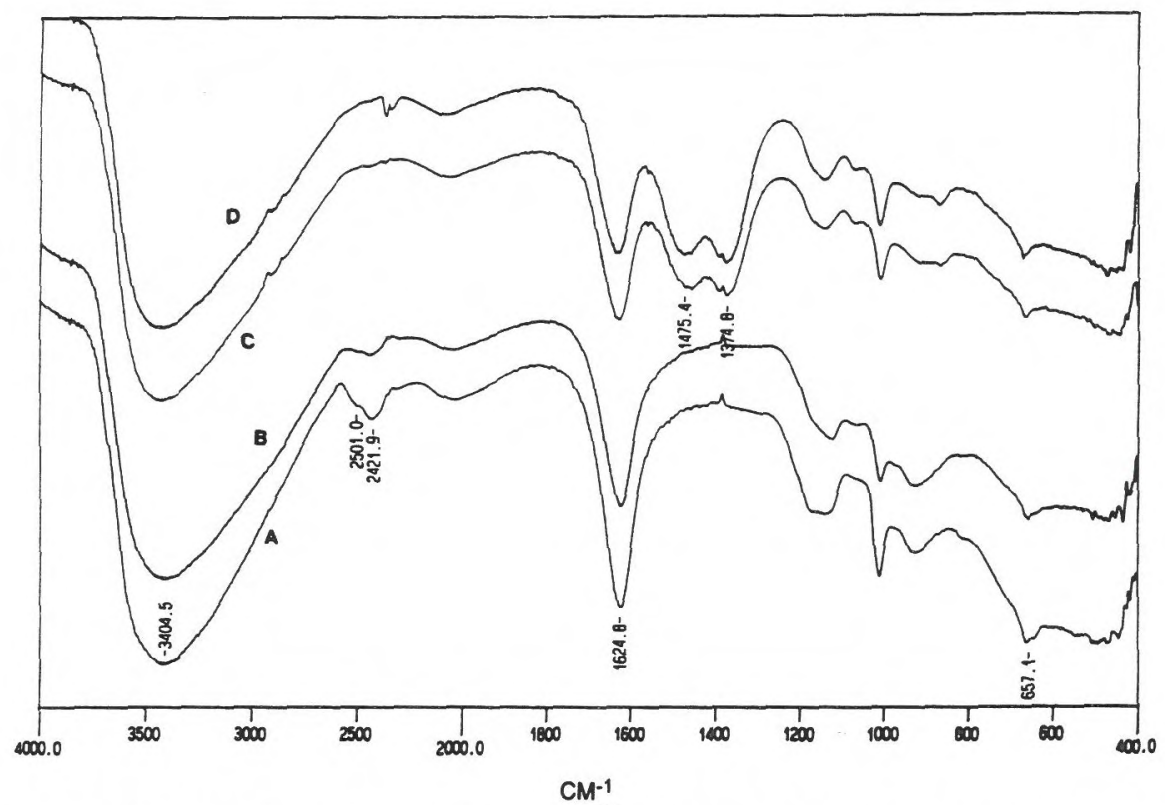

FIG. 2. FT.IR spectra of stoichiometric samples. pH values: $A=4.2 ; B=7.2 ; C=11.0 ; D=11.8$. 


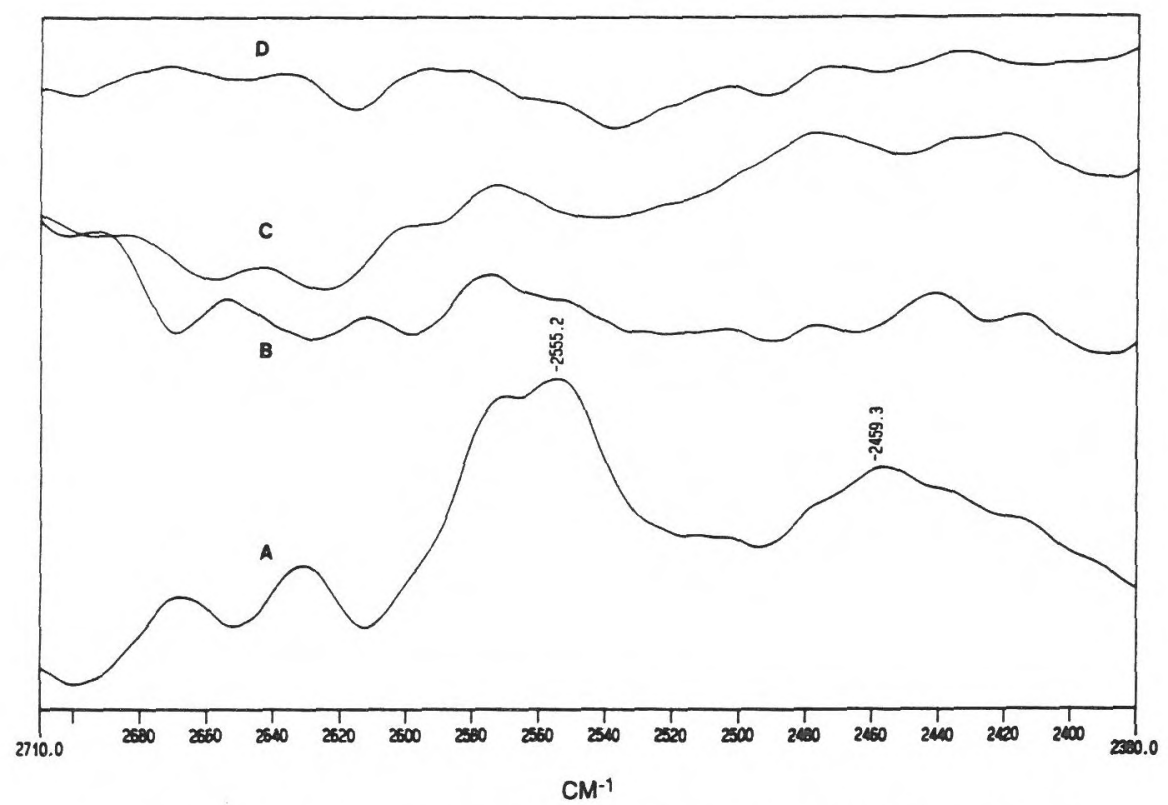

FIG. 3. FT-Raman spectra of stoichiometric samples. pH values: $A=4.2 ; B=7.2 ; C=11.0 ; D=11.8$.

\section{(a) Stoichiometric Samples}

In contact with water the $\mathrm{ZnS}$ surface will be hydrated (6). If carbon dioxide is present, $\equiv \mathrm{ZnOHCO}_{2}$ is formed:

$$
\begin{aligned}
\equiv \mathrm{Zn}+\mathrm{H}_{2} \mathrm{O}+\mathrm{CO}_{2} \rightarrow & \equiv \mathrm{ZnOHCO}{ }_{2} \\
\equiv \mathrm{S} & \equiv \mathrm{SH}
\end{aligned}
$$

(see Figs. 2 and 3). The broad absorption band at 1475$1375 \mathrm{~cm}^{-1}$ due to $\equiv \mathrm{ZnOHCO}_{2}$ bend is present in spectra of the alkaline samples but is absent in acidic or neutral samples.

The absorption bands at 2502 and $2424 \mathrm{~cm}^{-1}$ due to the S-H stretch can be seen even in spectra of alkaline samples if the $\mathrm{pH}$ is not higher than 10 (the $\mathrm{p} K_{\mathrm{a}}=10.28$ for $\equiv \mathrm{SH}$ (6)); the bands grow stronger as the $\mathrm{pH}$ is lowered. In the Raman spectra the bands at 2555 and $2459 \mathrm{~cm}^{-1}$ are recognized only in the acidic sample. This indicates that, as proposed by Rönngren et al. (6), an ion exchange will take place during acidic conditions and thereby increase the number of $\equiv \mathrm{S}-\mathrm{H}$ sites:

$$
\begin{array}{ll}
\equiv \mathrm{ZnSH}+2 \mathrm{H}^{+} \rightarrow & \equiv \mathrm{ZnSH}+\mathrm{H}_{2} \mathrm{O}+\mathrm{Zn}^{2+} \\
\equiv \mathrm{ZnOH} & \equiv \mathrm{SH} .
\end{array}
$$

The bands at $1100-1000 \mathrm{~cm}^{-1}$ and $630 \mathrm{~cm}^{-1}$ are due to oxidation products. The nature and oxidation state of these sulfur species are not known. In the assignment (Table 1) of these bands they are compared with sulfate even if sulfate would be too soluble to stay on the surface. The presence of two values for the S-H stretch indicates that there are two kinds of S-H groups. They can be represented as $\equiv \mathrm{Zn}-\mathrm{SH}$ and

$$
\begin{aligned}
& \equiv \mathrm{Zn} \\
& \equiv \mathrm{SH}
\end{aligned}
$$

The former is an adsorbed group, in closer contact with the solution; it is therefore more easily oxidized. The latter belongs to the bulk, signifying a certain protection against oxidation:

$$
\begin{array}{ll}
\equiv \mathrm{ZnSH} & \equiv \mathrm{ZnS}_{x} \mathrm{O}_{y} \\
\equiv \mathrm{SH}+(\mathrm{O}) \rightarrow & \equiv \mathrm{SH} \\
\equiv \mathrm{ZnSH} & \equiv \mathrm{ZnS}_{x} \mathrm{O}_{y} \\
\equiv \mathrm{SH} & \equiv \mathrm{SH}
\end{array}
$$

\section{(b) Samples Made with Excess $S^{2-}$}

The vibration arising from the $\mathrm{S}-\mathrm{H}$ stretching mode can be seen in all IR and Raman spectra (see Figs. 4 and 5). 


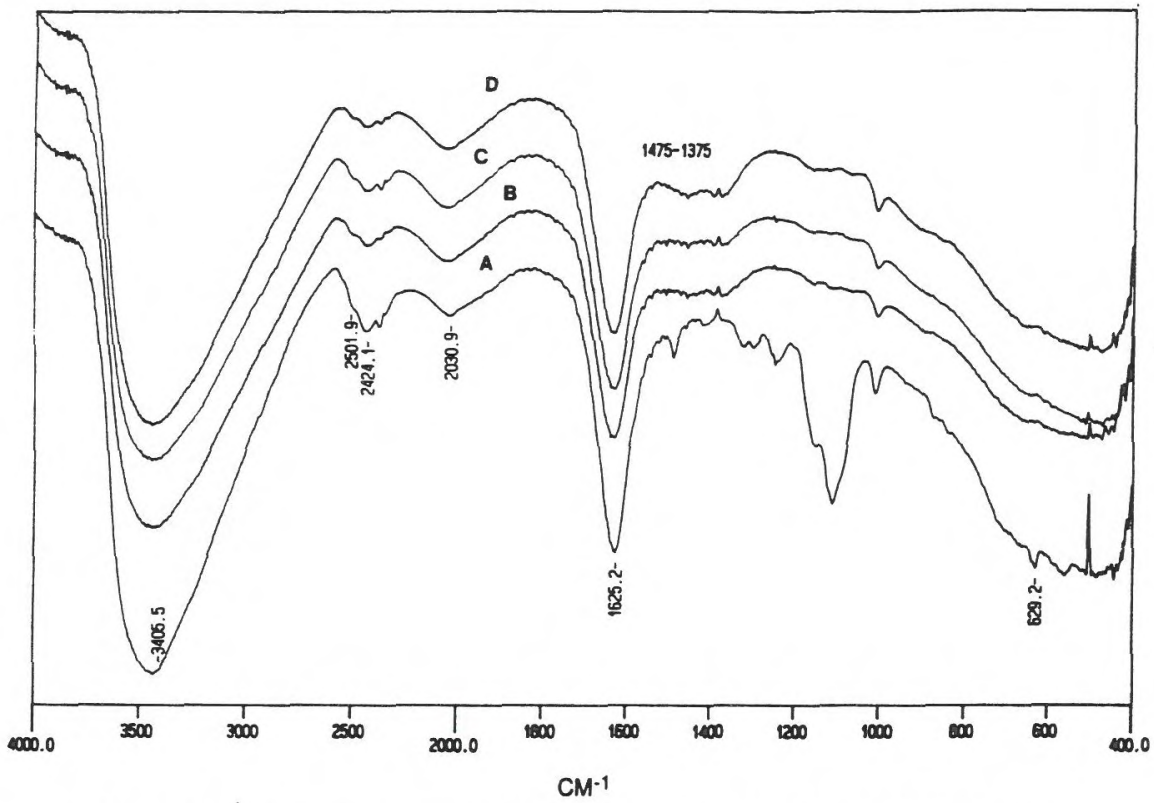

FIG. 4. FT-IR spectra of samples made with excess $\mathrm{S}^{-2}$. pH values: $A=2.7 ; B=9.2 ; C=9.8 ; D=10.2$.

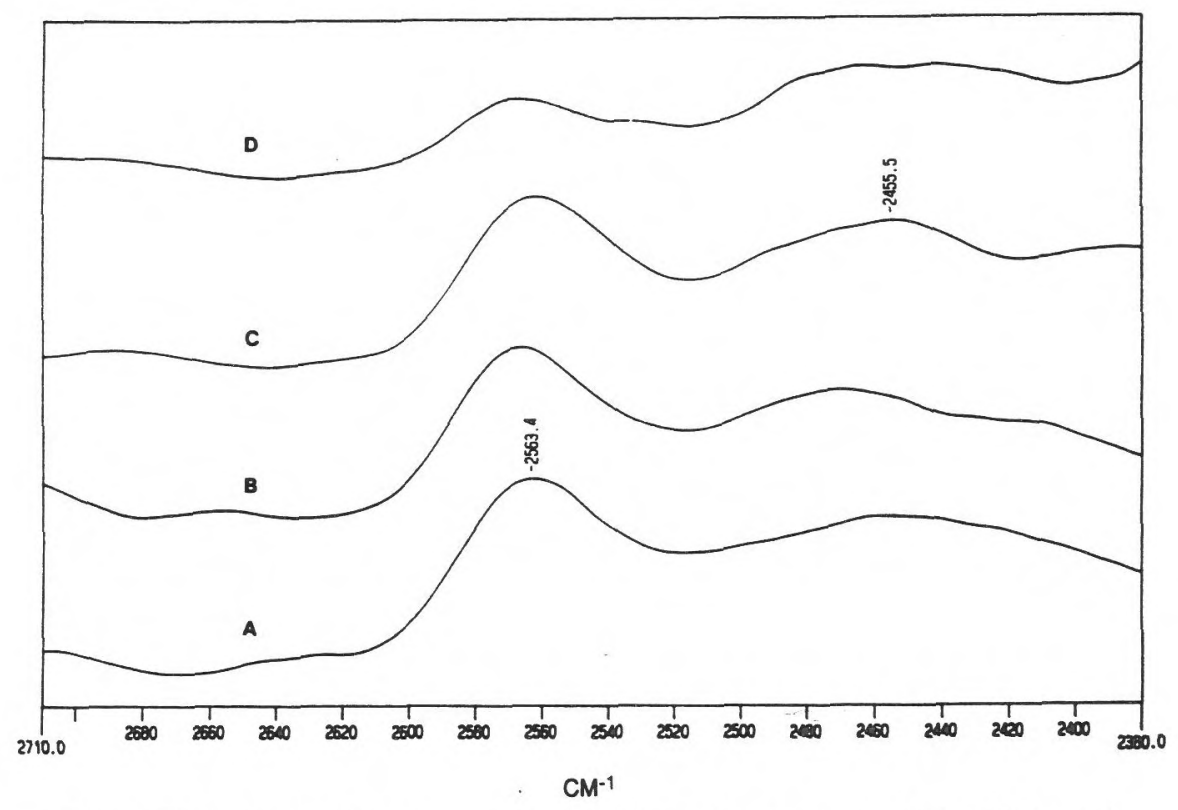

FIG. 5. FT-Raman spectra of samples made with excess $\mathrm{S}^{-2}$. pH values: $A=2.7 ; B=9.2 ; C=9.8: D=10.2$. 
Since the surface was originally covered by sulfide ions it is expected that contact with water will produce $\mathrm{S}-\mathrm{H}$ groups at most of the sites. Even in the most alkaline sample ( $\mathrm{pH}$ 10.2 ) some of the sulfur sites are expected to be protonated:

$$
\begin{aligned}
& \Longrightarrow \mathrm{S} \quad+\mathrm{H}_{2} \mathrm{O} \rightarrow \equiv \mathrm{S}+\mathrm{OH}^{-} \\
& \equiv \mathrm{ZnS}^{-} \quad \equiv \mathrm{ZnSH} \text {. }
\end{aligned}
$$

The vibration origination from $\equiv \mathrm{ZnOHCO}_{2}$ can be seen in the most alkaline samples. If the $\mathrm{pH}$ is high enough some $\mathrm{OH}^{-}$will manage to compete with $\mathrm{HS}^{-}$for the $\mathrm{Zn}$-sites, thereby producing the $\equiv \mathrm{Zn}-\mathrm{OH}$ group which will be changed to $\equiv \mathrm{ZnOHCO}_{2}$ when $\mathrm{CO}_{2}$ is adsorbed:

$$
\begin{aligned}
& \Longrightarrow \mathrm{S} \quad \equiv \mathrm{S} \\
& \equiv \mathrm{ZnSH}+\mathrm{OH}^{-}+\mathrm{CO}_{2} \rightarrow \equiv \mathrm{ZnOHCO}_{2}+\mathrm{HS}^{-} \\
& \equiv \mathrm{SH} \quad \equiv \mathrm{SH} \\
& \equiv \mathrm{ZnS}^{-} \quad \equiv \mathrm{ZnS}^{-} \text {. }
\end{aligned}
$$

The excess sulfide ions will cover the mineral surface and prevent oxidation of $\mathrm{ZnS}$ in alkaline solutions. When the $\mathrm{pH}$ is low some $\mathrm{H}^{+}$will react with $\mathrm{S}^{2-}$ to produce $\mathrm{H}_{2} \mathrm{~S}(\mathrm{~g})$ :

$$
\begin{array}{ll}
\equiv \mathrm{ZnSH}+2 \mathrm{H}^{+} \rightarrow & \equiv \mathrm{SH}+\mathrm{H}_{2} \mathrm{~S}(\mathrm{~g})+\mathrm{Zn}^{2+} \\
\equiv \mathrm{SZnSH} & \equiv \mathrm{SH} .
\end{array}
$$

The evolution of $\mathrm{H}_{2} \mathrm{~S}(\mathrm{~g})$ may result in oxidation of some of the $\equiv \mathrm{S}-\mathrm{H}$ groups. Other $\mathrm{S}-\mathrm{H}$ groups are more protected and thereby not affected:

$$
\begin{array}{ll}
\equiv \mathrm{SH} \quad+(\mathrm{O}) \rightarrow & \equiv \mathrm{SH} \\
\equiv \mathrm{ZnSH} & \equiv \mathrm{ZnS}_{x} \mathrm{O}_{y} .
\end{array}
$$

\section{(c) Samples Made with Excess of $\mathrm{Zn}^{2+}$}

At high $\mathrm{pH} \equiv \mathrm{ZnOHCO}_{2}$ will be formed (see Figs. 6 and 7):

$$
\begin{aligned}
\equiv \mathrm{SZn}^{+}+\mathrm{OH}^{-}+2 \mathrm{CO}_{2} & \rightarrow \\
\equiv \mathrm{ZnOH} & \equiv \mathrm{SZnOHCO}_{2} \\
& \equiv \mathrm{ZnOHCO}_{2} .
\end{aligned}
$$

At lower $\mathrm{pH}$ an ion exchange reaction will take place between surface $\mathrm{Zn}^{2+}$ ions and $\mathrm{H}^{+}$in solution:

$$
\begin{array}{ll}
\equiv \mathrm{ZnSZn}^{+}+3 \mathrm{H}^{+} & \rightarrow \equiv \mathrm{ZnSH}+2 \mathrm{Zn}^{2+}+\mathrm{H}_{2} \mathrm{O} \\
\equiv \mathrm{SZnOHCO}_{2} & \equiv \mathrm{SH}+\mathrm{CO}_{2} .
\end{array}
$$

Due to the excess of $\mathrm{Zn}^{2+}$ in the solution, the redox level is higher and most of the $\mathrm{S}-\mathrm{H}$ groups that are formed through ion exchange reaction will be oxidized. The Raman spectra show that even under these conditions some $\mathrm{S}-\mathrm{H}$ groups still exist (nothing can be found in the IR spectra):

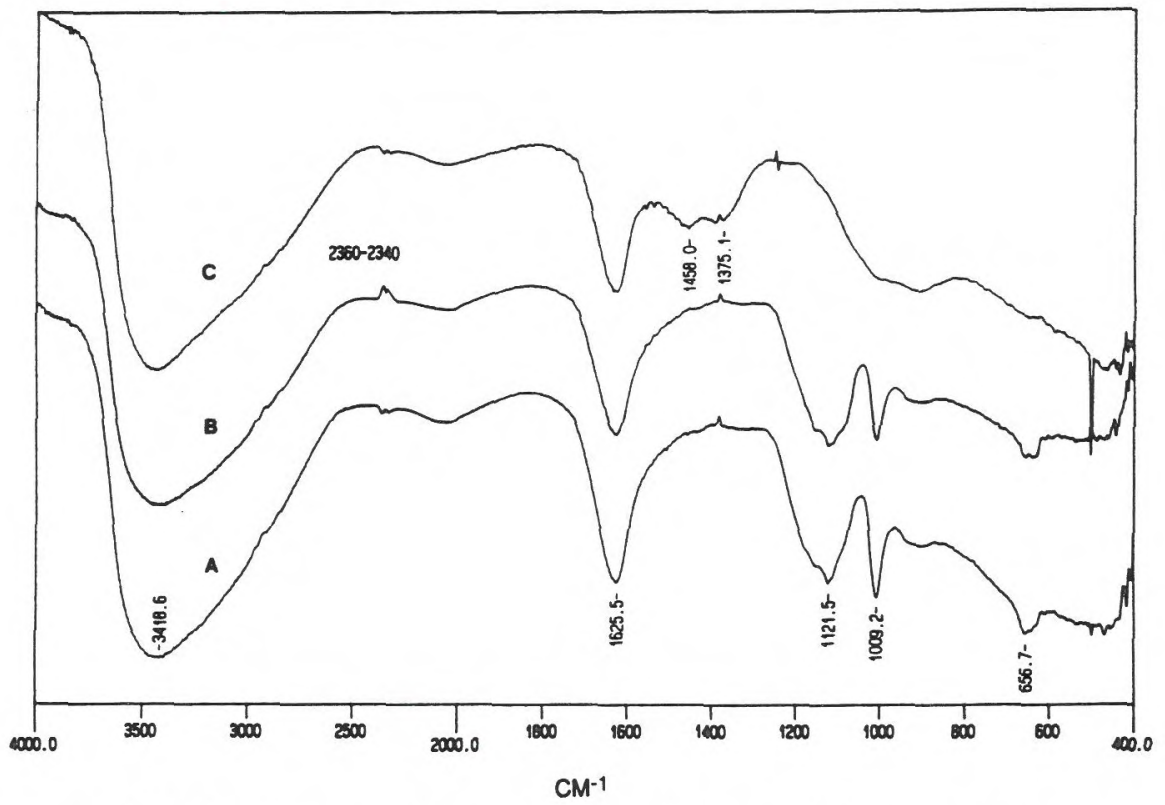

FIG. 6. FT-IR spectra of samples made with excess of $\mathrm{Zn}^{2+}$. $\mathrm{pH}$ values: $A=4.0 ; B=4.5 ; C=8.8$. 


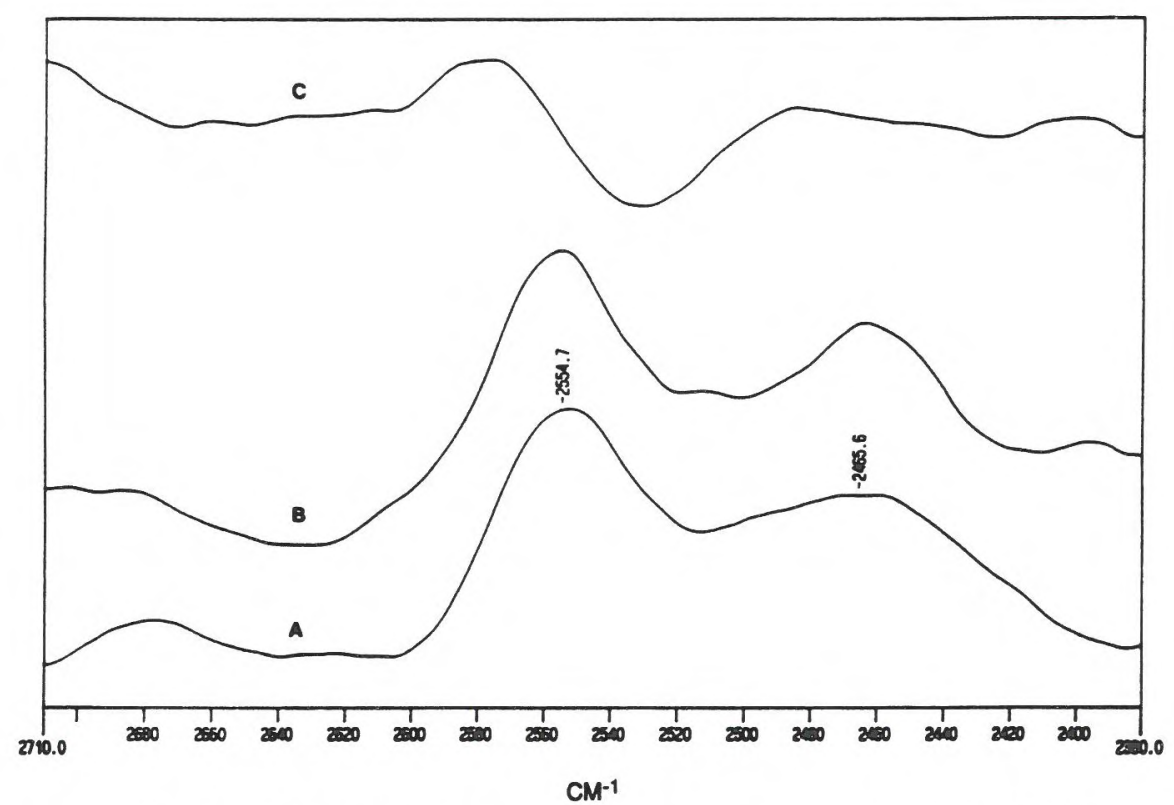

FIG. 7. FT-Raman spectra of samples made with excess of $\mathrm{Zn}^{2+}$. $\mathrm{pH}$ values: $A=4.0 ; B=4.5 ; C=8.8$.

$$
\begin{array}{ll}
\equiv \mathrm{ZnSH} & \equiv \mathrm{ZnS}_{x} \mathrm{O}_{y} \\
\equiv \mathrm{SH}+(\mathrm{O}) \rightarrow & \equiv \mathrm{S}_{x} \mathrm{O}_{y}+2 \mathrm{H}_{2} \mathrm{O} \\
& \equiv \mathrm{ZnS}_{x} \mathrm{O}_{y} \\
\Rightarrow \mathrm{ZnSH} & \equiv \mathrm{SH} .
\end{array}
$$

\section{CONCLUSIONS}

At varied pH's, $\mathrm{S}-\mathrm{H}$ and $\mathrm{ZnOHCO} 2$ groups can be detected by vibration spectroscopy. The $\mathrm{S}-\mathrm{H}$ bands appear at 2501-2422 $\mathrm{cm}^{-1}$ (FT-IR) and 2555-2459 $\mathrm{cm}^{-1}$ (FT-Raman). The band with $\mathrm{ZnOHCO}_{2}$ is found at $1475-1375$ $\mathrm{cm}^{-1}$ (FT-IR).

In stoichiometric samples the $\Longrightarrow \mathrm{SH}$ group can be identified over a broad $\mathrm{pH}$ range. The signal from the $\mathrm{S}-\mathrm{H}$ stretch becomes stronger with decreasing pH. Under alkaline conditions the $\equiv \mathrm{ZnOHCO}_{2}$ group appears.

Also, in samples made with excess of $\mathrm{S}^{2-}$ the $\equiv \mathrm{SH}$ group exists at all $\mathrm{pH}$ values. At the highest $\mathrm{pH}$ values the $\equiv \mathrm{ZnOHCO} 2$ group is detected.

In samples made with excess of $\mathrm{Zn}^{2+}$ the $\equiv \mathrm{SH}$ group can be detected only in the Raman spectra of the acidic samples. At higher $\mathrm{pH}$ values the $\equiv \mathrm{ZnOHCO}_{2}$ group exists.

Oxidation of some $\equiv \mathrm{SH}$ groups, leading to the formation of some not very soluble sulfur species on the mineral surface, is detected in all samples except for the alkaline one with excess of $\mathrm{Zn}^{2+}$.
Vibration spectroscopy is a useful tool for the evaluation of surface reactions on $\mathrm{ZnS}$, provided that the particle size is small enough.

\section{REFERENCES}

1. Mosley, M. H., in "Laboratory Methods in Infrared Spectroscopy" (R. G. J. Miller and B. C. Stace, Eds), p. 31. Heyden, Philadelphia, 1972.

2. Schindler, P. W., and Kamber, H. R., Helv. Chim. Acta 51, 1781 (1968).

3. Schindler, P. W., and Gamsjäger, H., Kolloid Z. Z. Polym. 250,759 (1972).

4. Stumm, W., Huang, C. P., and Jinkens, S. R., Croat. Chem. Acta 42, 223 (1970).

5. Sun, Z. X., Forsling, W., Rönngren, L., and Sjobberg, S., Int. J. Miner. Process. 33, 83 ( 1991 ).

6. Rönngren, L., Sjöberg, S., Sun, Z. X., Forsling, W., and Schindler, P. W., J. Colloid Interface Sci. 145, 396 (1991).

7. Sun, Z. X., Forsling, W., Rönngren, L., and Sjöberg, S., Colloids Surf. 59, 243 ( 1991 ).

8. Murphy, G. M., and Vance, J. E., J. Chem. Phys. 6, 426 (1938).

9. Tursi, A. J., and Nixon, E. R., J. Chem. Phys. 53, 518 (1970).

10. Acquista, N., and Schoen, L. J., J. Chem. Phys. 53, 1290 (1970).

11. Petty, C. J., Warnes, G. M., Hendra, P. J., and Judkins, M., Spectrochim. Acta. Part A 47, 1179 (1991).

12. Gadsden, J. A., in "Infrared Spectra of Minerals and Related Inorganic Compounds" p. 15. Butterworths, London, 1975.

13. Nakamoto, K., in "Infrared and Raman Spectra of Inorganic and Coordination Compounds," p. 112. Wiley, New York, 1986.

14. Nakamoto, K., in "Infrared and Raman Spectra of Inorganic and Coordination Compounds," p. 248. Wiley, New York, 1986.

15. Lutz, H. D., Pobitschka, W., Frischemeimer, B., and Becker, R. A., Appl. Spectrosc. 32, 541 (1978). 
II 


\section{FT-IR and FT-Raman Studies of Colloidal ZnS}

2. Sorption of amyl xanthate at the $\mathrm{ZnS} /$ water interface

Rune Gärd, Zhong-Xi Sun and Willis Forsling

Department of Inorganic Chemistry,

Luleå University of Technology

S-971 87 Luleå, Sweden 


\section{ABSTRACT}

Sorption of amyl xanthate onto colloidal $\mathrm{ZnS}$ has been studied, using FT-IR and FT-Raman techniques. The effects of $\mathrm{pH}$ and initial concentration of xanthate on the adsorbed amount and on the distribution of acidic and alkaline sites are evaluated. Two different models for the sorption are suggested. The first one involves an ion exchange between $\mathrm{Zn}^{2+}$ and $\mathrm{H}^{+}$and a subsequent precipitation of solid zinc amylxanthate:

$$
\begin{aligned}
\equiv \mathrm{SZnOH}+2 \mathrm{H}^{+}+2 \mathrm{AX}^{-} \rightarrow & \equiv \mathrm{SH}+\mathrm{Zn}(\mathrm{AX})_{2}(\mathrm{~s})+\mathrm{H}_{2} \mathrm{O} \\
\equiv \mathrm{ZnSH} & \equiv \mathrm{ZnSH}
\end{aligned}
$$

The second one involves the ion exchange between $\mathrm{HCO}_{3}{ }^{-}$and $\mathrm{AX}^{-}$ followed by adsorption of xanthate at the zinc site:

$$
\begin{array}{ll}
\equiv \mathrm{SZnOHCO}_{2}+\mathrm{AX}^{-} \rightarrow & \equiv \mathrm{SZnAX}+\mathrm{HCO}_{3}^{-} \\
\equiv \mathrm{ZnSH} & \equiv \mathrm{ZnSH}
\end{array}
$$

Botn reactions induce increased sorption at lower $\mathrm{pH}$. A low $\mathrm{pH}$ will enhance the ion exchange between $\mathrm{Zn}^{2+}$ and $\mathrm{H}^{+}$, which will result in precipitation of zinc amyl xanthate. This statement is supported by SOLGASWATER calculations and by spectral evidence. At low $\mathrm{pH}$ the formation of $\mathrm{CO}_{2}(\mathrm{~g})$ will force reaction (2) to the right, implying higher adsorption. 


\section{INTRODUCTION}

The complexation of xanthate type collectors at the surface of sulphide minerals plays an important role in the flotation process. However, the interpretation of flotation mechanisms suffers from the complexity of surface complexation. The identification of the formed surface species is a central research topic in flotation chemistry. With the development of powerful surface analytical instruments, like FT-IR and FT-Raman spectrometers, one has gained a useful tool for the studies of reactions at the mineral/water interface. As presented in a previous paper [1], the absorption bands originating from $\equiv \mathrm{SH}$ and $\equiv \mathrm{ZnOHCO}_{2}$ were identified in the spectra of colloidal zinc sulphide, which provided basic evidence for the surface acid/base properties of the compound. These sites are formed according to the reactions:

$$
\begin{gathered}
\equiv \mathrm{SH} \leftrightarrow \equiv \mathrm{S}^{-}+\mathrm{H}^{+} \\
\text {and } \\
\equiv \mathrm{ZnOHCO}_{2}+\mathrm{H}^{+} \leftrightarrow \equiv \mathrm{ZnOH}_{2}^{+}+\mathrm{CO}_{2}(\mathrm{aq})
\end{gathered}
$$

an will consequently be referred to as the acidic and the alkaline site, respectively. The presence of xanthate ions in a flotation system will probably dramatically influence the surface acid-base properties of zinc sulphide. The aims of this work are to investigate the nature of the complexes that are formed at the surface of metal sulphides in the presence of xanthate ions and consequently induce mineral floatability and to describe how xanthate ions affect the complexation at the zinc sulphide/water interface. The understanding of the adsorption mechanisms of xanthate ions at the surface of zinc sulphide will not only offer an explanation to sphalerite complexation itself, but may also throw some light on xanthate complexation at the surface of other sulphide minerals, that are not so well suited for IR studies due to their opaqueness. As well known, short carbon chain xanthates can be only weakly adsorbed at the surface of zinc sulphide. Therefore we have chosen to work with amyl xanthate, which is a common collector for sphalerite.

IR studies of xanthate at the surface of sulphide minerals, pioneered by Little and Leja [2], Little et al. [3,4], Leja et al. [5] and Poling and Leja [6], has been the subject of many investigations. Cases and his collaborates have made great contributions to the understanding of the interaction between potassium amylxanthate and galena [7-11] or pyrite 
$[12,13]$ in relation to flotation. They regard the adsorption on galena to be a two stage process. The grinding conditions $(\mathrm{pH}$, wet or dry) are considered to have a great influence on the formed surface species. Depending on the conditions dixanthogen, stoichiometric lead xanthate, non-stoichiometric lead xanthate or monocoordinated xanthate is found to be the dominating species. For pyrite they have found that ferric xanthate is formed if iron is present (through the use of iron rods at the grinding) while dixantogen dominates if no iron is present. Due to the works by Ray et al. [14], Mattes and Pauleickhoff [15,16] and Colthup and Porter Powell [17] the vibrational modes of xanthates have been evaluated. However still new progress is being made, most recently by Persson [18], Ihs et al. [19] and Woods et al.[20] who have detected chemisorbed xanthate at metal sulphide, gold electrode, and metal surfaces respectively.

Compared to the abundant IR studies on xanthate-sulphide surface complexes, Raman studies are rear. In this investigation the emphasis is laid on the combination of IR and Raman in the study of surface reactions. The effect of amyl xanthate ions on the acidic and alkaline sites of colloidal zinc sulphide as a function of $\mathrm{pH}$ and initial xanthate concentration is discussed as well as the reaction model for sorption of xanthate.

\section{EXPERIMENTAL}

All the chemicals in this study were reagent pure. The potassium amyl xanthate (KAX) was provided by Hoechst and proved to be almost 100 $\%$ pure when tested spectrophotometrically at 226 and $301 \mathrm{~nm}$ for the $\varepsilon$ -value. The pH's of the suspensions were adjusted with dilute $\mathrm{HClO}_{4}$ and $\mathrm{NaOH}$ solutions.

\section{Sample Conditioning}

Four sets of experiments were performed, each with different initial concentration of $\operatorname{KAX}(0.1,1,10$, and $100 \mathrm{mM})$.

The $\mathrm{ZnS}$ precipitates were made by adding sodium sulfide solution (100 $\mathrm{mM})$ to $20 \mathrm{ml}$ of zinc nitrate solution $(100 \mathrm{mM})$ until a $\mathrm{pH}$ of 8.6 was obtained (the $\mathrm{pH}_{\mathrm{zpc}}$ of $\mathrm{ZnS}$ is 8.6 [30]). The BET surface area of the formed zinc sulphide was $115.0 \mathrm{~m}^{2} / \mathrm{g}$, based on two measurements. The suspensions were vacuum filtered $(0.2 \mu \mathrm{m})$ and rinsed several times with deionized water and then transferred to flasks with $40 \mathrm{ml}$ of $\mathrm{KAX}$ solutions with $0.10 \mathrm{M} \mathrm{NaClO}$. The pH's were adjusted and the suspensions were stirred for $18 \mathrm{~h}$, whereafter $\mathrm{pH}$ 's were measured, the suspensions were rinsed with $40 \mathrm{ml}$ of destilled water and filtered and 
dried. Finally FT-IR and FT-Raman spectra of the samples were recorded.

A reference sample was made by adding $40 \mathrm{ml} 0.065 \mathrm{M} \mathrm{Zn}\left(\mathrm{NO}_{3}\right)_{2}$ solution and $0.8 \mathrm{~g} \mathrm{KAX}$ to $1.0 \mathrm{~g}$ of $\mathrm{ZnS}$, filtering the suspension and finally drying the solid phase in a dessicator.

\section{Instrumentation}

A Perkin-Elmer FT-IR $1760 \mathrm{X}$ spectrometer and a Perkin-Elmer NIR FT-Raman $1700 \mathrm{X}$ spectrometer were used in this study.

The UVspectra were recorded on a Perkin-Elmer Lamda $2 S$ UV/VIS spectrometer.

The BET-measurements were made with a Micromeretics ASAP 2000.

\section{FT-IR Measurements (DRIFT)}

Samples of $5 \% \mathrm{ZnS}$ mixed with $\mathrm{KBr}$ were placed in a small container, where they were struck by source radiation which was diffusely reflected in various directions. This radiation was measured with a TGS detector against a reference spectrum of pure powdered $\mathrm{KBr}$. Typically 32 scans were accumulated at $4 \mathrm{~cm}^{-1}$ resolution.

\section{FT-Raman Measurements}

The samples were excited with $100 \mathrm{~mW}$ of unpolarised, intensitystabilized $(0.1 \% \mathrm{rms}) 1064 \mathrm{~nm}$ radiation from a Spectron SL 301 series Nd:YAG laser, and the scattered light collected with $180^{\circ}$ backscattering geometry optics. The InGaAs detector and integral preamplifier were cooled to $77 \mathrm{~K}$ (liquid nitrogen), as this yields a fourfold gain in signal-to-noise performance. The interference filters, used to reject light at the excitation wavelength, allowed collection of scattered light with a Raman shift greater than $-200 \mathrm{~cm}^{-1}$. The mirror drive speed was $0.1 \mathrm{~cm} / \mathrm{s}$ and 100 scans were accumulated at $4 \mathrm{~cm}^{-1}$ resolution. The Raman spectra presented in this paper have been corrected for instrumental response as a function of wavelength. This was done primarily to avoid gross misinterpretation of relative peak heights. The correlation method used was that of Petty et al. [21]. The emission source in this procedure was an electric tube furnace loaded with crushed ceramics, at a temperature of $1373 \pm 5 \mathrm{~K}$ (integral thermocouple rated at $1550 \mathrm{~K}$ ).

\section{RESULTS}

The absorption bands are often highly coupled [17,18,22] and it is therefore not always possible to assign them to a specific vibration. In 
table 1 the vibrations, giving the greatest contributions to the absorption bands, are presented.

Effect of the total KAX concentration and $\mathrm{pH}$ on the acidic site

Fig. 1 shows IR-spectra of amyl xanthate sorbed on $\mathrm{ZnS}$ at four different total concentrations of $\operatorname{KAX}(0.1,1,10$ and $100 \mathrm{mM})$. A-D at $\mathrm{pH}=$ $9.66 \pm 0.15$ and $\mathrm{E}-\mathrm{H}$ at $\mathrm{pH}=6.65 \pm 0.35$.

A pervading feature is that the absorption band originating from the $\mathrm{S}-\mathrm{H}$ stretch increases in intensity when the initial KAX concentration is raised and the $\mathrm{pH}$ is lowered.

At $\mathrm{pH}=9.66 \pm 0.14$, the weak band at $2419 \mathrm{~cm}^{-1}$, due to the $\mathrm{S}-\mathrm{H}$ stretch $[1,26,27]$ appears only in the spectrum of the $100 \mathrm{mM}$ sample. At $\mathrm{pH}=6.65 \pm 0.35$ it is relatively strong in the spectrum of the $100 \mathrm{mM}$ sample and weaker in the spectrum of the $10 \mathrm{mM}$ sample. Figs. 2 and 3 show the IR-spectra of amyl xanthate sorbed on $\mathrm{ZnS}$ at varying $\mathrm{pH}$ and at four different $\mathrm{KAX}$ concentrations $(3 \mathrm{~A}-\mathrm{D}=10 \mathrm{mM}, 3 \mathrm{E}-\mathrm{H}=100$ $\mathrm{mM}, 5 \mathrm{~A}-\mathrm{C}=0.1 \mathrm{mM}$ and $5 \mathrm{D}-\mathrm{F}=1.0 \mathrm{mM}$ ). The vibration from the $\mathrm{SH}$ bond is highly $\mathrm{pH}$ dependent. At the highest KAX concentration (100 $\mathrm{mM}$ ) the intensity is clearly decreasing when $\mathrm{pH}$ is raised but it exists even at $\mathrm{pH}=9.8$. At $10 \mathrm{mM}$ the $\mathrm{S}-\mathrm{H}$ stretch can be detected at $\mathrm{pH} \leq 8.8$. At $1.0 \mathrm{mM}$ it appears as a very weak band only in the spectrum of the most acidic sample $(\mathrm{pH}=6.7)$ but it doesn't exist in the spectra of the $0.1 \mathrm{mM}$ samples.

Effect of the total $\mathrm{KAX}$ concentration and $\mathrm{pH}$ on the alkaline site The IR-bands at 1446 and $1375 \mathrm{~cm}^{-1}$, due to vibrations in the $\mathrm{ZnOHCO}_{2}$ entity [1] are present only at high $\mathrm{pH}$ and low initial $\mathrm{KAX}$ concentrations. According to fig. 1 they are medium strong at the lowest $\mathrm{KAX}$ concentrations at $\mathrm{pH}=9.66 \pm 0.15$. At the same $\mathrm{pH}$ they are becoming weaker at $10 \mathrm{mM}$ and disappear at $100 \mathrm{mM}$. At the highest KAX concentrations the bands at 1460 and $1379 \mathrm{~cm}^{-1}$, originating from vibrations in the hydrocarbon chain appear. Although these bands and the $\equiv \mathrm{ZnOHCO}_{2}$ bands are obtained in about the same position they can easily be distinguished from each other due to the different shapes. As can be seen in fig. 3 the $\equiv \mathrm{ZnOHCO}_{2}$ bands are medium strong at low total KAX concentrations $(0.1$ or $1.0 \mathrm{mM})$ and high $\mathrm{pH}(9.5$ or 8.2$)$ but disappear when $\mathrm{pH}$ was lower. 
Effect of $p H$ and the total KAX concentration on the amount of sorbed xanthate

It is obvious that more xanthate has reacted at low $\mathrm{pH}$ and high total KAX concentration. Fig.4 shows Raman-spectra of amyl xanthate sorbed on $\mathrm{ZnS}$ with four different total concentrations of $\operatorname{KAX}(0.1,1.0$, 10 and $100 \mathrm{mM}$ ). A-D at $\mathrm{pH}=9.66 \pm 0.15$ and $\mathrm{E}-\mathrm{H}$ at $\mathrm{pH}=6.65 \pm 0.35$ (Fig. 1 shows the corresponding IR-spectra). Xanthate can be detected in the IR-spectra (the bands at around 2900, 1460, 1379 and 1216-1048 $\mathrm{cm}^{-1}$ ) only at the two highest concentrations. Among the Raman spectra, only the $100 \mathrm{mM}$ samples show any xanthate (the bands at 1448, 1126 and $1054 \mathrm{~cm}^{-1}$ ). Fig. 5 demonstrates the Raman-spectra of amyl xanthate sorbed on $\mathrm{ZnS}$ at varying $\mathrm{pH}$ and at two different $\mathrm{KAX}$ concentrations (A-D $=10 \mathrm{mM}$ and $\mathrm{E}-\mathrm{H}=100 \mathrm{mM}$ ). The corresponding IR-spectra are shown in fig. 2. At a total KAX concentration of 100 $\mathrm{mM}$ the IR-spectra show strong bands at $\mathrm{pH}=7.0$, that become continuously weaker when $\mathrm{pH}$ is raised. The corresponding Ramanspectra exhibit strong absorption bands at $\mathrm{pH}=7.0$ and 7.3 but very weak ones for $\mathrm{pH}=8.5$ and 9.8 . At $10 \mathrm{mM}$ only the spectra of the two most acidic samples exhibit any xanthate vibrations.

\section{Comparison with the vibration spectrum of $\mathrm{Zn}(A X)_{2}(s)$}

A comparison of the IR-spectrum obtained of the $\mathrm{Zn}(\mathrm{AX})_{2}$ reference (Fig. 6A) with the spectra of the samples (Figs. 1 and 2) shows that the band at $1044 \mathrm{~cm}^{-1}$ (mostly $\mathrm{v}_{\mathrm{a}}\left(\mathrm{CS}_{2}\right)[17,22]$ ) is shifted up by 4 wavenumbers and has no splitting. The band at $1132 \mathrm{~cm}^{-1}$ (mostly $v$ (COC) [17]) is shifted down by 6 wavenumbers and the band at 1208 $\mathrm{cm}^{-1}$ (mostly $\mathrm{v}\left(\mathrm{COC}\right.$ ) [17]) is shifted up by $8 \mathrm{~cm}^{-1}$.

A comparison between the corresponding Raman spectra (Figs. 6B and 4 and 5 respectively) reveals that the absorption band at $1043 \mathrm{~cm}^{-1}$ is shifted up by 12 wavenumbers, while the band at $1131 \mathrm{~cm}^{-1}$ is shifted down by 5 wavenumbers. The band at $1207 \mathrm{~cm}^{-1}$ in $\mathrm{Zn}(\mathrm{AX})_{2}$ is lost in the spectra of the samples.

\section{The water bands}

The IR absorption bands at $1614 \mathrm{~cm}^{-1}$, due to the $\mathrm{HOH}$ bend [23] and at around $3370 \mathrm{~cm}^{-1}$, due to the $\mathrm{OH}$ stretch [23] in water, are virtually unaffected by variation in $\mathrm{KAX}$ concentration and $\mathrm{pH}$.

The broad bands at around $2045 \mathrm{~cm}^{-1}$ that exist in all the spectra of alkaline samples and at $2093 \mathrm{~cm}^{-1}$ in the spectra of the most "acidic" samples made with an initial $\mathrm{KAX}$ concentration of $100 \mathrm{mM}$ are association (combination) bands of water. Lutz et al. [24] have assigned 
them to the transition $v_{2}+v_{R}$ where $v_{2}$ is the bending mode and $v_{R}$ is a librational mode.

\section{DISCUSSION}

Effect of $\left[\mathrm{AX}^{-}\right]$and $\mathrm{pH}$ on the acidic site

In contact with water the sulphur sites are protonated [29,30,31] (reaction 5). Furthermore more $\mathrm{SH}$-bonds will be produced at low $\mathrm{pH}$ according to the ion exchange reaction (6):

$$
\begin{aligned}
& \equiv \mathrm{Zn}+\mathrm{H}_{2} \mathrm{O} \rightarrow \quad \equiv \mathrm{ZnOH} \\
& \equiv \mathrm{S} \quad \equiv \mathrm{SH} \\
& \equiv \mathrm{SZnOH}+2 \mathrm{H}^{+} \rightarrow \quad \equiv \mathrm{SH}+\mathrm{H}_{2} \mathrm{O}+\mathrm{Zn}^{2+} \\
& \equiv \mathrm{SH} \\
& \equiv \mathrm{SH}
\end{aligned}
$$

This ion exchange mechanism offers an explanation to the stronger $\mathrm{SH}$ bands at higher KAX concentrations. When zinc ions are leaving the surface and $\mathrm{Zn}(\mathrm{AX})_{2}(\mathrm{~s})$ precipitate is formed, new protonated sulphur sites are exposed:

$$
\begin{aligned}
& \equiv \mathrm{SZnOH}+2 \mathrm{AX}^{-}+2 \mathrm{H}^{+} \rightarrow \equiv \mathrm{SH}+\mathrm{H}_{2} \mathrm{O}+\mathrm{Zn}(\mathrm{AX})_{2}(\mathrm{~s}) \\
& \equiv \mathrm{SH} \\
& \equiv \mathrm{SH}
\end{aligned}
$$

Hence, precipitation of $\mathrm{Zn}(\mathrm{AX})_{2}$ will result in a higher abundance of $\mathrm{SH}$-bonds at the mineral surface.

Majima [32] reported the $\mathrm{pK}_{\mathrm{a}}$ for amyl xanthic acid to be 1.72 . Therefore it's not likely that the $\mathrm{SH}$ group originates from xanthic acid. It can also be seen in the ATR spectrum (Fig. 6) of a $50 \mathrm{mM} \mathrm{KAX-}$ solution at $\mathrm{pH}=4.4$, that no absorption bands exist in the 2400-2500 $\mathrm{cm}^{-1}$ region (the bands at 2340 and $2360 \mathrm{~cm}^{-1}$ are due to carbon dioxide in the air).

\section{Effect of total KAX concentration and $p H$ on the alkaline site}

Rönngren et al. [30] and Sun et al. [29] have discussed the conditions for formation of Brönstedt alkaline sites at aqueous $\mathrm{ZnS}$ surfaces in accordance with potentiometric titrations. They concluded the alkaline site to be $\equiv \mathrm{ZnOH}$. This is probably correct if the experimental set-up is closed and no $\mathrm{CO}_{2}$ can enter the system. Recently we have shown the existence of alkaline sites using FT-IR spectroscopic methods [1]. 
However, in that case and in this work, as in real flotation, the system is exposed to air which will inevitably lead to dissolution of $\mathrm{CO}_{2}$. The nature of the alkaline site will include a mixture of carbonate and hydroxide, which can be denoted $\equiv \mathrm{ZnOHCO}_{2}$. Of course this site will be even more pronounced at higher $\mathrm{pH}$. In the presence of amyl xanthate competition for the zinc sites between $\mathrm{AX}^{-}$and $\mathrm{HCO}_{3}^{-}$will take place, leading to desorption of $\mathrm{HCO}_{3}^{-}$:

$\equiv \mathrm{ZnOHCO}_{2}+\mathrm{AX}^{-} \rightarrow \equiv \mathrm{ZnAX}+\mathrm{HCO}_{3}^{-}$

\section{Effect of $\mathrm{pH}$ on the amount of sorbed xanthate}

At low $\mathrm{pH}$ protons will react with the alkaline sites to produce carbon dioxide and water and thereby create new zinc sites that can adsorb xanthate ions:

$\equiv \mathrm{ZnOHCO}_{2}+\mathrm{H}^{+} \rightarrow \equiv \mathrm{ZnOH}_{2}^{+}+\mathrm{CO}_{2}(\mathrm{aq})$

Because of the ion exchange $\mathrm{H}^{+} / \mathrm{Zn}^{2+}$ that is discussed earlier, a lower $\mathrm{pH}$ also leads to an enhanced precipitation of $\mathrm{Zn}(\mathrm{AX})_{2}$.

\section{Sorption mechanism}

It is not clear whether the dominating sorption mechanism is precipitation or adsorption. Persson [18] and Valli et al. [22] have discussed the shifts in wavenumbers for the xanthate functional group on sorption onto sulphide mineral surfaces. They have found similar shifts as we have and assigned these changes to adsorption of what they call "type 2 " where the xanthate is bidentate or bridgingly co-ordinated to the zinc sites. Ihs et al. [19] and Woods et al.[20] have studied adsorption of ethyl xanthate on to gold and have found an upward wavenumber shift for the band around $1200 \mathrm{~cm}^{-1}$, which they consider to be typical for chemisorption of xanthate. Hence, the wavenumber shifts in our spectra indicate that chemisorption is involved.

However, the very intense absorption bands cannot possibly originate from vibrations in an adsorbed monolayer alone. There has to be some contribution from other species e.g. precipitated $\mathrm{Zn}(\mathrm{AX})_{2}$ as well. The increase in intensity of the SH-bands at high total KAX concentrations indicate that precipitation is involved, especially at low $\mathrm{pH}$ and high total KAX concentrations.

The key questions are: What is the adsorption capacity in the system? How much $\mathrm{Zn}^{2+}$ can be released from the mineral surface? 
The concentration of $\mathrm{Zn}$ sites can be estimated using the following equation [33]:

$$
Z n_{\text {surf }}=\frac{S \cdot n_{f} \cdot n_{s}}{N_{A} \cdot v^{2 / 3}} \quad\left(\mathrm{~mol} / \mathrm{dm}^{3}\right)
$$

where $S=115$ is the specific surface area of the solid $\left(\mathrm{m}^{2} / \mathrm{g}\right), n_{f}=2$ is the number of surface $\mathrm{Zn}$ per unit cell [30], $n_{s}=1$ is the number of zinc sites per $\mathrm{ZnS}, N_{A}$ is Avogadro's constant, and $v=1.58 \cdot 10^{-28}$ is the volume of the unit cell $\left(\mathrm{m}^{3}\right)$. Then $\mathrm{Zn}_{\text {surf }}$ is $1.3 \mathrm{mmoles} / \mathrm{g} \mathrm{ZnS}$.

Even with the xanthates standing upright at the surface it is impossible to attach a xanthate ion at every surface zinc site, due to the size of the xanthate ion.

The monolayer capacity, $\mathrm{Q}_{\mathrm{m}}$ may be estimated according to the following equation [7]:

$$
Q_{m}=\frac{1}{A^{\prime}} \cdot \frac{1}{N_{A}} \cdot S \quad(\mathrm{~mol} / \mathrm{g})
$$

Where $A^{\prime}=2.88 \cdot 10^{-19}[34]$ is the cross-sectional area of the adsorbent $\left(\mathrm{m}^{2}\right), N_{A}$ is Avogadro's constant and $S=115$ is the specific surface area $\left(\mathrm{m}^{2} / \mathrm{g}\right)$. According to that calculation the monolayer capacity will amount to $0.66 \mathrm{mmoles} / \mathrm{g} \mathrm{ZnS}$. This value is about half of the value for $\mathrm{Zn}_{\text {surf }}$, so there might be many inactive zinc sites.

In a separate test the capacity for sorption by the precipitated $\mathrm{ZnS}$ was evaluated. $0.1 \mathrm{~g}$ of $\mathrm{ZnS}$ was added to flasks containing $30 \mathrm{ml}$ of $5 \mathrm{mM}$ $\mathrm{KAX}$, each at a different $\mathrm{pH}$. After 60 minutes the residual KAX concentration was measured spectrophotometrically at $301 \mathrm{~nm}$. As can be seen from fig. 7 colloidal $\mathrm{ZnS}$ can withdraw -1.5 mmoles of amylxanthate/g $\mathrm{ZnS}$ from solution. This figure is to be compared to the estimations of the monolayer capacity of 0.66 mmoles and the number of zinc sites (1.3 mmoles). So there is a substantial amount of zinc sites that are unoccupied by xanthate and at the same time, more than a monolayer of xanthate has reacted. Some of the excess xanthate may have been adsorbed in a second layer but a precipitation of $\mathrm{Zn}(\mathrm{AX})_{2}$ is even more plausible. The steep slope of the sorption curve in fig. 7 also indicates that precipitation is involved.

The surface zinc ions with no xanthate co-ordinated may leave the surface and, on accumulation near to it, form solid zinc xanthate which, adsorbs to the surface. 
Some doubts could be raised if the concentration of $\mathrm{Zn}^{2+}$ is sufficient for $\mathrm{Zn}(\mathrm{AX})_{2}$ precipitation. Therefore a calculation with the SOLGASWATER program was undertaken. The matrix used for the calculation is presented in table 2 and the result of the calculations in fig. 8. As can be seen in fig. $8 \mathrm{Zn}(\mathrm{AX})_{2}$ is precipitated if the $\mathrm{pH}$ is lower than $~ 9.5$. However, adsorption of xanthate is not taken into account, since we lack a constant for that reaction.

We have found no dixanthogen, which is consistent with the works of Leja [3] and others.

\section{The water bands}

Sorption of xanthate doesn't seem to interfere with the bound water since the absorption bands connected with water posses about the same intensity regardless of $\mathrm{pH}$ and total $\mathrm{KAX}$ concentration.

\section{CONCLUSIONS}

More xanthate is sorbed at low $\mathrm{pH}$ and high total KAX concentrations. At these conditions, the formation of SH-groups indicates that zinc ions have been dissolved from the zinc sulphide surface, exposing new sulphur sites, at which protons can be adsorbed and precipitation of $\mathrm{Zn}(\mathrm{AX})_{2}$ (s) is formed.

The disappearance of the $\equiv \mathrm{SZnOHCO}_{2}$-groups at high total $\mathrm{KAX}$ concentrations and high $\mathrm{pH}$ indicates that xanthate ions are adsorbed at the alkaline sites, replacing $\mathrm{HCO}_{3}^{-}$.

The sorption process does not influence surface bound water. 


\section{REFERENCES}

1. Gärd, R., Sun Z.X. and Forsling, W., J. Colloid Interface Sci. 169, 393 (1995).

2. Little, L.H. and Leja, J., Proc. 2nd Int. Congr. Surface Activity. Vol III, p. 261-266. Butterworths, London (1957).

3. Little, L.H., Poling, G.W. and Leja, J., Can. J. Chem. 39, 745 (1961).

4. Little, L.H., Poling, G.W. and Leja, J., Can. J. Chem. 39, 1783 (1961).

5. Leja, J., Little, L.H. and Poling, G.W., Trans. I.M.M., 72, 407-423 (1963).

6. Poling, G.W. and Leja, J., J. Phys. Chem. 67, 2121 (1963).

7. De Donato, P., Cases, J.M., Kongolo, M., Michot, L. and Burneau, A., Colloids Surfaces 44, 207 (1990).

8. Cases, J.M., Kongolo, M., De Donato, P., Michot, L. and Erre, R., Int. J. Miner. Process. 28, 313 (1990).

9. Cases, J.M., Kongolo, M., De Donato, P., Michot, L. and Erre, R., Int. J. Miner. Process. 30, 35 (1990).

10. Kongolo, M., Cases, J.M., De Donato, P., Michot, L. and Erre, R., Int. J. Miner. Process. 30, 195 (1990).

11. Cases, J.M. and De Donato, P., Int. J. Miner. Process., 33, 49 (1991).

12. Cases, J.M., De Donato, P., Kongolo, M. and Michot, L., Colloids Surfaces 36, 323 (1989).

13. Cases, J.M., De Donato, P., Kongolo, M. and Michot, L., 3rd International Symposium on Beneficiation and Agglomeration, Bhubaneswar, India, 16-18 Jan. (1991). 
14. Ray, A., Sathyanarayana, D.N., Prasad, G.D. and Patel, C.C., Spectrochim. Acta. 29A, 1579 (1973).

15. Mattes, R., and Pauleickhoff, G., Spectrochim. Acta 29A, 1339 (1973).

16. Mattes, R., and Pauleickhoff, G., Spectrochim. Acta 30A, 379 (1974).

17. Colthup, N.B. and Porter Powell, L., Spectrochim. Acta. 43A, 317 (1987).

18. Persson, P., Thesis. Swedish University of Agricultural Sciences. (1990).

19. Ihs, A., Uvdal, K. and Liedberg, B., Langmuir. 9, 733-739 (1993)

20. Woods, R., Kim, D.S. and Yoon, R.-H., Colloids Surf. A: Physiochem. Eng. Aspects. 94, 67-74 (1995).

21. Petty, C.J., Warnes, G.M., Hendra, P.J. and Judkins, M., Spectrochim. Acta. 47A, 1179 (1991).

22. Valli, M., Persson, P. and Persson, I., Acta Chem. Scandinavica. 48, 810 (1994).

23. Gadsden, J.A., in "Infrared spectra of minerals and related inorganic compounds", p 15, Butterworth.1975.

24. Lutz, H.D., Pobitschka, W., Frischemeimer, B. and Becker, R.A., Appl. Spectrosc. 32, 541-547 (1978).

25. Nakamoto, K., "Infrared and Raman spectra of inorganic and coordination compounds", p 112, John Wiley \& sons, Inc. 1986.

26. Tursi, A.J. and Nixon, E.R., J. Chem. Phys. 53, 518 (1970).

27. Acquista, N. and Schoen, L.J., J. Chem. Phys. 53, 1290 (1970).

28. Murphy, G.M. and Vance, J.E., J. Chem. Phys. 6, 426 (1938). 
29. Sun, Z.X., Forsling, W., Rönngren, L. and Sjöberg, S., Int. J. Mineral Processing., 33, 83 (1991).

30. Rönngren, L., Sjöberg, S., Sun, Z.X., Forsling, W. and Schindler, P.W., J. Colloid Interface Sci. 145, 396 (1991).

31. Sun, Z.X., Forsling,W., Rönngren, L., Sjöberg, S. and Schindler, P.W., Colloids Surf. 59, 243 (1991).

32. Majima, H., Sci. Rep. Inst. Tohuku Univ., Series A., 13, no. 3, 183197 (1961).

33. Chan, D., Perram, J.W., White, L.R. and Healy, T.W., J. Chem. Soc. Faraday Trans. 1, 1046 (1975).

34. Granville, A., Finkelstein, N.P. and Allison, S.A., Trans. I.M.M. 81, (1972).

35. Smith, R.M. and Martell, A.E., "Critical Stability constants", Vol. 4,5 and 6, Plenum Press, New York (1976, 1982, 1989).

36. Fuerstenau, M.C., US Bureau of Mines Info. Circ., 8818, 7 (1980). 


\section{LEGENDS TO FIGURES}

Fig. 1. FT-IR spectra of samples with varying total KAX concentration. $\mathrm{A}-\mathrm{D}$ at $\mathrm{pH}=9.66 \pm 0.15 . \mathrm{E}-\mathrm{H}$ at $\mathrm{pH}=6.65 \pm 0.35$. KAX concentrations: $A=0.1 \mathrm{mM}, \mathrm{B}=1.0 \mathrm{mM}, \mathrm{C}=10.0 \mathrm{mM}, \mathrm{D}=100 \mathrm{mM}$, $\mathrm{E}=0.1 \mathrm{mM}, \mathrm{F}=1.0 \mathrm{mM}, \mathrm{G}=10.0 \mathrm{mM}$ and $\mathrm{H}=100 \mathrm{mM}$. The ordinate scale is identical for all spectra.

Fig. 2. FT-IR spectra of samples with varying $\mathrm{pH}$. A-D at $10 \mathrm{mM}, \mathrm{E}-\mathrm{H}$ at $100 \mathrm{mM}$ total $\mathrm{KAX}$ concentration. $\mathrm{pH}$-values: $\mathrm{A}=10.9, \mathrm{~B}=8.8, \mathrm{C}=$ $6.3, \mathrm{D}=5.6, \mathrm{E}=9.8, \mathrm{~F}=8.5, \mathrm{G}=7.3$ and $\mathrm{H}=7.0$. The ordinate scale is identical for all spectra.

Fig. 3. FT-IR spectra of samples with varying $\mathrm{pH}$. A-C at $0.1 \mathrm{mM}, \mathrm{D}-\mathrm{F}$ at $1.0 \mathrm{mM}$ total $\mathrm{KAX}$ concentration. $\mathrm{pH}$-values: $\mathrm{A}=9.5, \mathrm{~B}=8.2, \mathrm{C}=$ $6.8, \mathrm{D}=9.6, \mathrm{E}=8.1, \mathrm{~F}=6.7$. The ordinate scale is identical for all spectra.

Fig. 4. FT-Raman spectra of samples with varying total KAX concentration. $\mathrm{A}-\mathrm{D}$ at $\mathrm{pH}=9.66 \pm 0.15 . \mathrm{E}-\mathrm{H}$ at $\mathrm{pH}=6.65 \pm 0.35$. $\mathrm{KAX}$ concentrations: $A=0.1 \mathrm{mM}, B=1.0 \mathrm{mM}, C=10.0 \mathrm{mM}, \mathrm{D}=100 \mathrm{mM}$, $\mathrm{E}=0.1 \mathrm{mM}, \mathrm{F}=1.0 \mathrm{mM}, \mathrm{G}=10.0 \mathrm{mM}$ and $\mathrm{H}=100 \mathrm{mM}$. The ordinate scale is identical for all spectra.

Fig. 5. FT-Raman spectra of samples with varying $\mathrm{pH}$. A-D at $10 \mathrm{mM}$, $\mathrm{E}-\mathrm{H}$ at $100 \mathrm{mM}$ total $\mathrm{KAX}$ concentration. $\mathrm{pH}$-values: $\mathrm{A}=10.9, \mathrm{~B}=$ 8.8, $\mathrm{C}=6.3, \mathrm{D}=5.6, \mathrm{E}=9.8, \mathrm{~F}=8.5, \mathrm{G}=7.3$ and $\mathrm{H}=7.0$. The ordinate scale is identical for all spectra.

Fig. 6. FT-IR (A) and FT-Raman (B) spectra of $\mathrm{Zn}(\mathrm{AX})_{2}(\mathrm{~s})$ precipitated in the presence of $\mathrm{ZnS}(\mathrm{s}) . \mathrm{C}=\mathrm{ATR}$-spectrum of a $50 \mathrm{mM}$ $\mathrm{KAX}$-solution at $\mathrm{pH}=4.40$ soaked into a filterpaper (the spectrum of the wet filterpaper is subtracted). The ordinate scale is arbitrary.

Fig. 7. Sorption curve for amylxanthate on colloidal $\mathrm{ZnS}$, showing the sorption capacity of $1.0 \mathrm{~g}$ as a function of $\mathrm{pH}$.

Fig. 8. The result of the SOLGASWATER calculations in the $\mathrm{Zn}^{2+}, \mathrm{H}^{+}$, $\equiv \mathrm{SZn}, \mathrm{AX}^{-}$and $\mathrm{S}^{2-}$ system. The matrix used is presented in table 2. 


\section{LEGENDS TO TABLES}

Table 1. Assignments of Absorption bands. Wavenumbers in $\mathrm{cm}^{-1}$.

Table 2. Matrix used for SOLGASWATER calculations in the $\mathrm{Zn}^{2+}$, $\mathrm{H}^{+}, \equiv \mathrm{SZn}, \mathrm{AX}^{-}$and $\mathrm{S}^{2-}$ system. 
TABLE 1

\begin{tabular}{cll} 
wavenumber, $\mathrm{cm}^{-1}$ & assignment & reference \\
1045 & $\mathrm{v}_{\mathrm{a}}\left(\mathrm{CS}_{2}\right)$ & $3,17,22$ \\
1133 & $\mathrm{v}(\mathrm{COC})$ & 3,17 \\
1204 & $\mathrm{v}(\mathrm{COC})$ & 3,17 \\
$1370-1460$ & $\equiv \mathrm{ZnOHCO}_{2}$ & 1 \\
1379 & $\delta_{\mathrm{s}}\left(\mathrm{CH}_{3}\right), \omega\left(\mathrm{CH}_{2}\right)$ & 17 \\
1458 & $\delta_{\mathrm{s}}\left(\mathrm{CH}_{2}\right), \delta_{\mathrm{a}}\left(\mathrm{CH}_{3}\right)$ & 17 \\
1614 & $\delta(\mathrm{HOH})$ & 23 \\
2045,2093 & $\mathrm{v}_{2}\left(\mathrm{H}_{2} \mathrm{O}\right)+\mathrm{v}_{\mathrm{R}}\left(\mathrm{H}_{2} \mathrm{O}\right)$ & 24 \\
$2343+2362$ & $\mathrm{v}_{3}\left(\mathrm{CO}_{2}\right)$ & 25 \\
2419 & $\mathrm{v}\left(\mathrm{SH}^{2}\right)$ & $1,26,27$ \\
2859 & $\mathrm{v}_{\mathrm{s}}\left(\mathrm{CH}_{2}\right)$ & 17 \\
2871 & $\mathrm{v}_{\mathrm{s}}\left(\mathrm{CH}_{3}\right)$ & 17 \\
2931 & $\mathrm{v}_{\mathrm{a}}\left(\mathrm{CH}_{2}\right)$ & 17 \\
2957 & $\mathrm{v}_{\mathrm{a}}\left(\mathrm{CH}_{3}\right)$ & 17 \\
3370 & $\mathrm{v}(\mathrm{OH})$ & 23 \\
\hline
\end{tabular}


TABLE 2

Species $\quad \log K_{f}$

Stoichiometry matrix

Ref.

\begin{tabular}{|c|c|c|c|c|c|c|c|c|}
\hline & & $\mathrm{Zn}^{2+}$ & ${ }^{+} \mathrm{H}^{+}$ & $\equiv \mathrm{SZn}$ & $\mathrm{AX}^{-}$ & $S^{2-}$ & Charge & \\
\hline $\mathrm{Zn}^{2+}$ & 0.00 & 1.0 & 0.0 & 0.0 & 0.0 & 0.0 & 0.0 & 35 \\
\hline $\mathrm{H}^{+}$ & 0.00 & 0.0 & 1.0 & 0.0 & 0.0 & 0.0 & 0.0 & 35 \\
\hline$\equiv \mathrm{SZn}$ & 0.00 & 0.0 & 0.0 & 1.0 & 0.0 & 0.0 & 0.0 & 35 \\
\hline $\mathrm{AX}^{-}$ & 0.00 & 0.0 & 0.0 & 0.0 & 1.0 & 0.0 & 0.0 & 35 \\
\hline$S^{2-}$ & 0.00 & 0.0 & 0.0 & 0.0 & 0.0 & 1.0 & 0.0 & 35 \\
\hline$\equiv \mathrm{SH}_{2}$ & 9.59 & -1.0 & 2.0 & 1.0 & 0.0 & 0.0 & 0.0 & 30 \\
\hline$\equiv \mathrm{SZnH}^{+}$ & 6.91 & 0.0 & 1.0 & 1.0 & 0.0 & 0.0 & 1.0 & 30 \\
\hline$\equiv \mathrm{SZnOH}^{-}$ & -10.28 & 0.0 & -1.0 & 1.0 & 0.0 & 0.0 & -1.0 & 30 \\
\hline $\mathrm{OH}^{-}$ & -14.00 & 0.0 & -1.0 & 0.0 & 0.0 & 0.0 & 0.0 & 35 \\
\hline HAX & 1.70 & 0.0 & 1.0 & 0.0 & 1.0 & 0.0 & 0.0 & 35 \\
\hline $\mathrm{ZnOH}^{+}$ & -9.00 & 1.0 & -1.0 & 0.0 & 0.0 & 0.0 & 0.0 & 35 \\
\hline $\mathrm{Zn}(\mathrm{OH})_{2}(\mathrm{aq})$ & -16.90 & 1.0 & -2.0 & 0.0 & 0.0 & 0.0 & 0.0 & 35 \\
\hline $\mathrm{Zn}(\mathrm{OH})_{3}^{-}$ & -28.40 & 1.0 & -3.0 & 0.0 & 0.0 & 0.0 & 0.0 & 35 \\
\hline $\mathrm{Zn}(\mathrm{OH})_{4}^{2-}$ & -41.20 & 1.0 & -4.0 & 0.0 & 0.0 & 0.0 & 0.0 & 35 \\
\hline $\mathrm{Zn}_{2} \mathrm{OH}^{3+}$ & -9.00 & 2.0 & -1.0 & 0.0 & 0.0 & 0.0 & 0.0 & 35 \\
\hline $\mathrm{HS}^{-}$ & 13.93 & 0.0 & 1.0 & 0.0 & 0.0 & 1.0 & 0.0 & 35 \\
\hline $\mathrm{H}_{2} \mathrm{~S}$ & 20.93 & 0.0 & 2.0 & 0.0 & 0.0 & 1.0 & 0.0 & 35 \\
\hline $\mathrm{Zn}(\mathrm{OH})_{2}(\mathrm{~s})$ & -11.76 & 1.0 & -2.0 & 0.0 & 0.0 & 0.0 & 0.0 & 35 \\
\hline $\mathrm{Zn}(\mathrm{AX})_{2}(\mathrm{~s})$ & 11.80 & 1.0 & 0.0 & 0.0 & 2.0 & 0.0 & 0.0 & 36 \\
\hline $\mathrm{ZnS}(\mathrm{s})$ & 25.00 & 1.0 & 0.0 & 0.0 & 0.0 & 1.0 & 0.0 & 35 \\
\hline
\end{tabular}




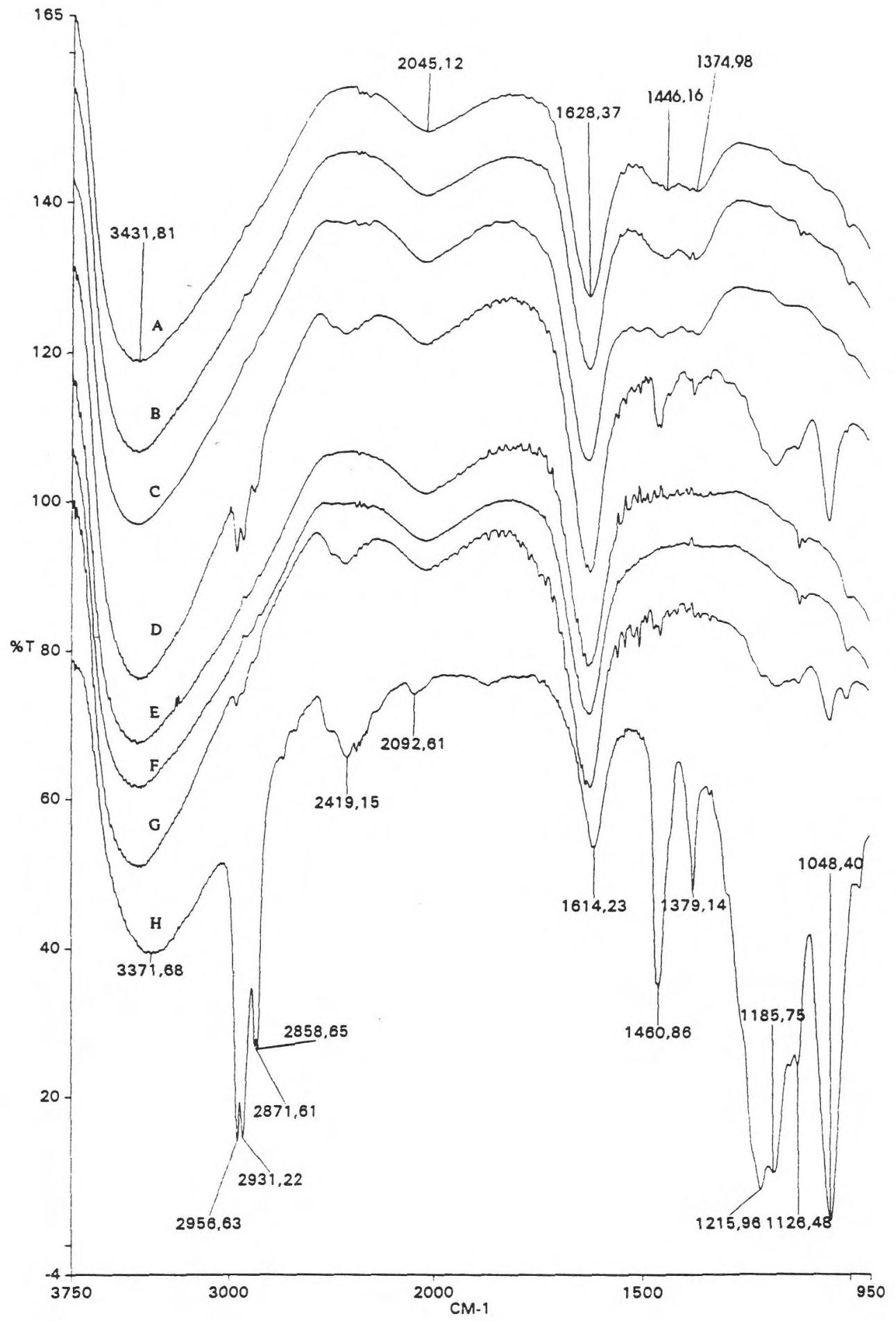

Fig. 1 


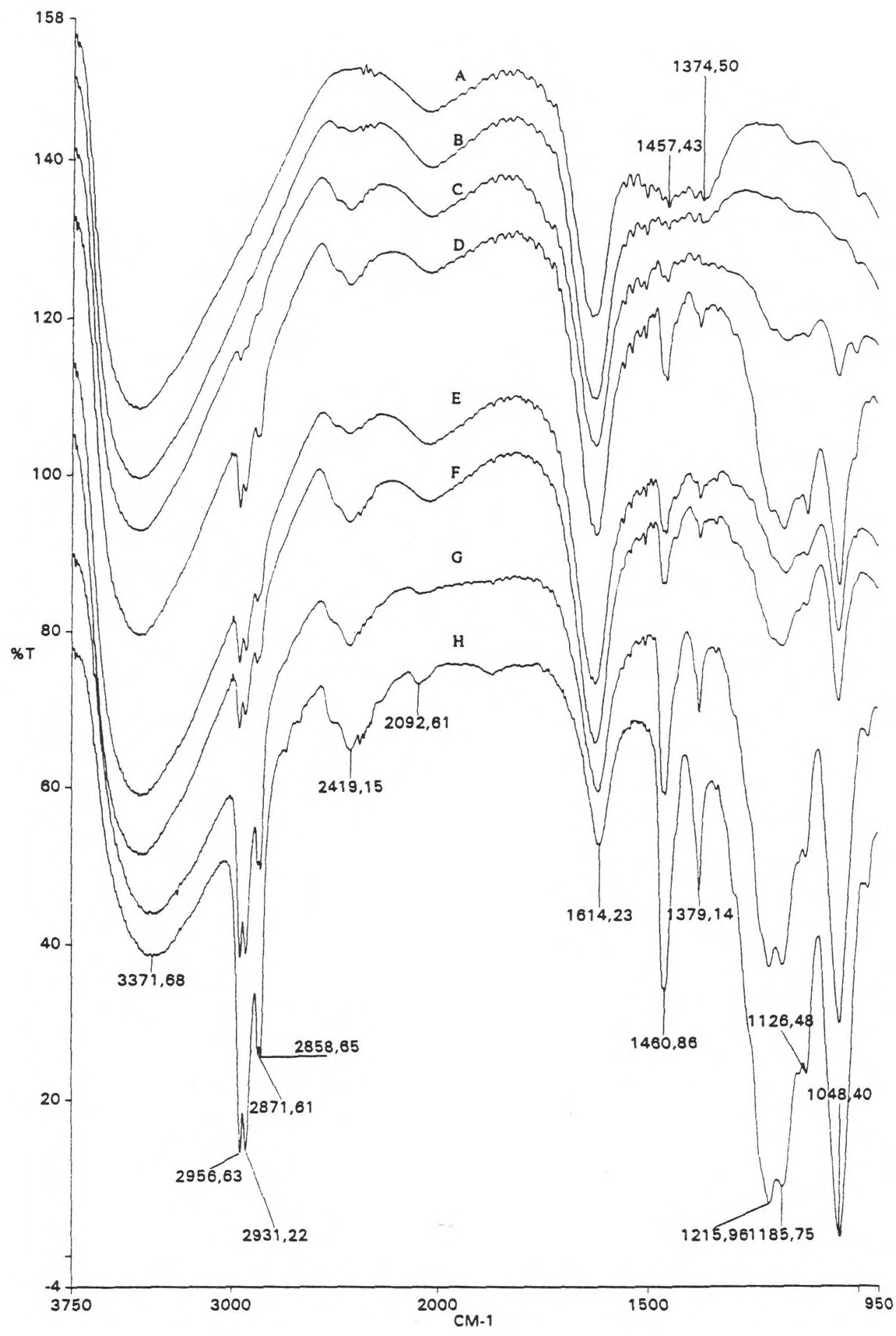

Fig. 2 


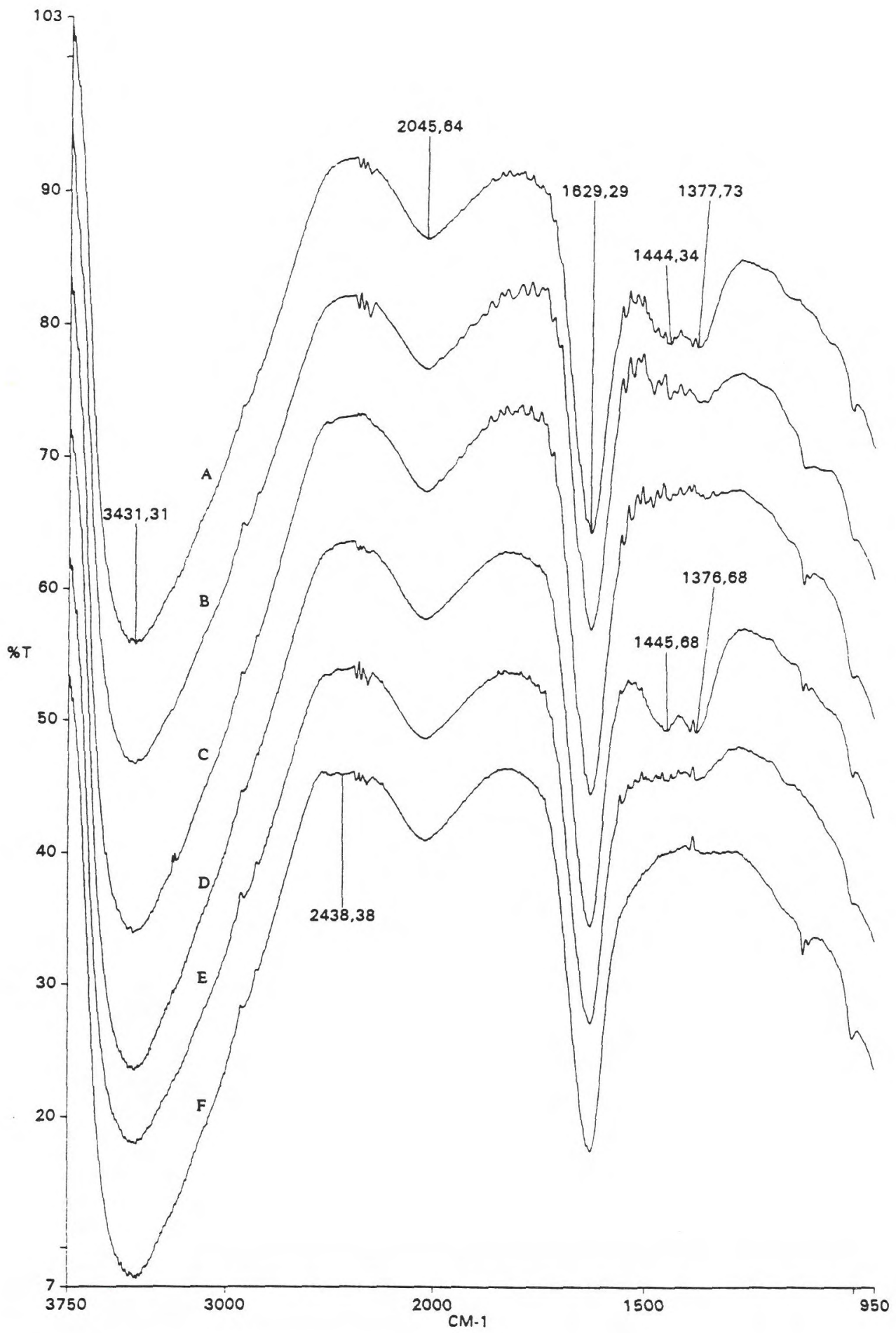

Fig. 3 


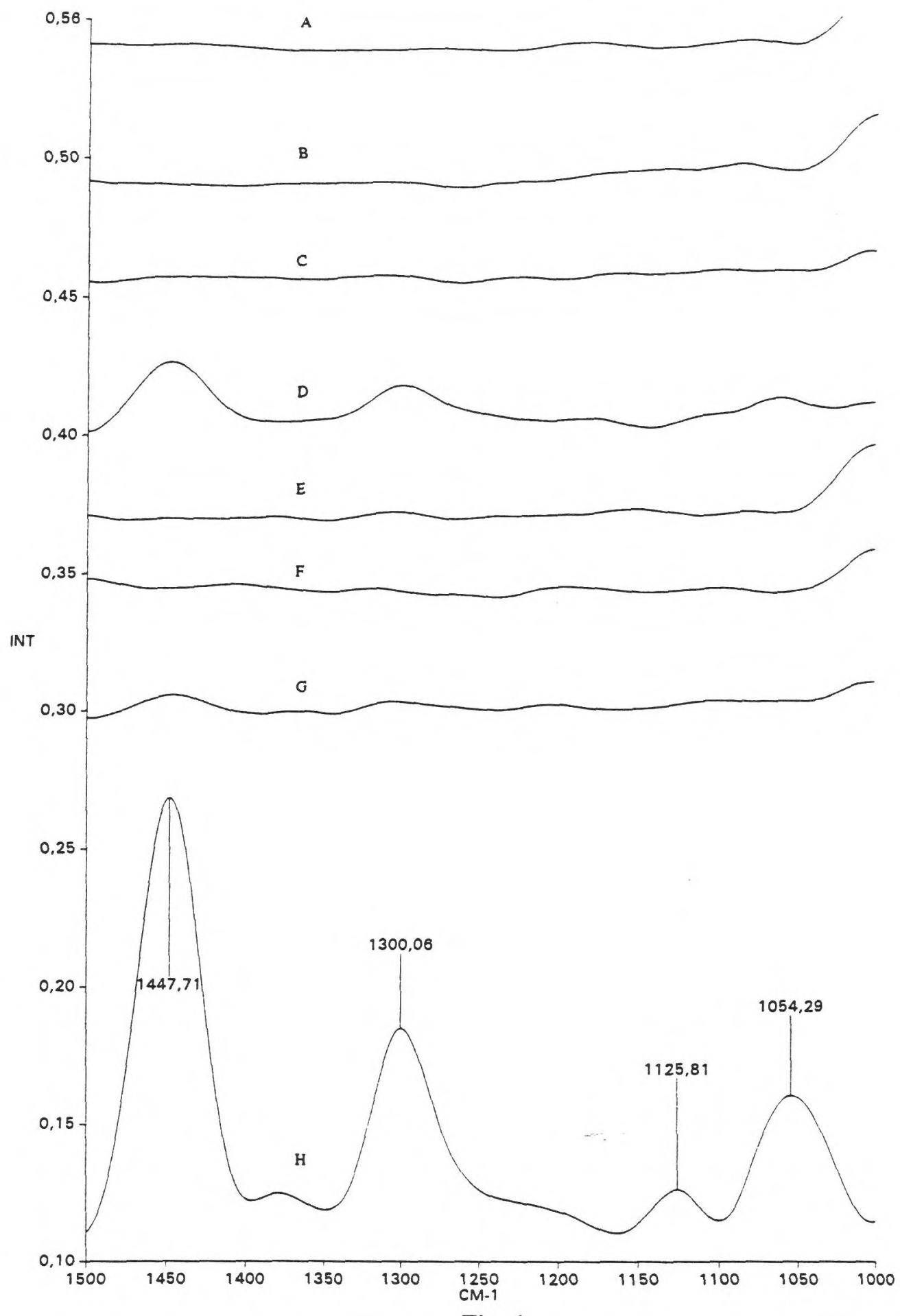

Fig. 4 


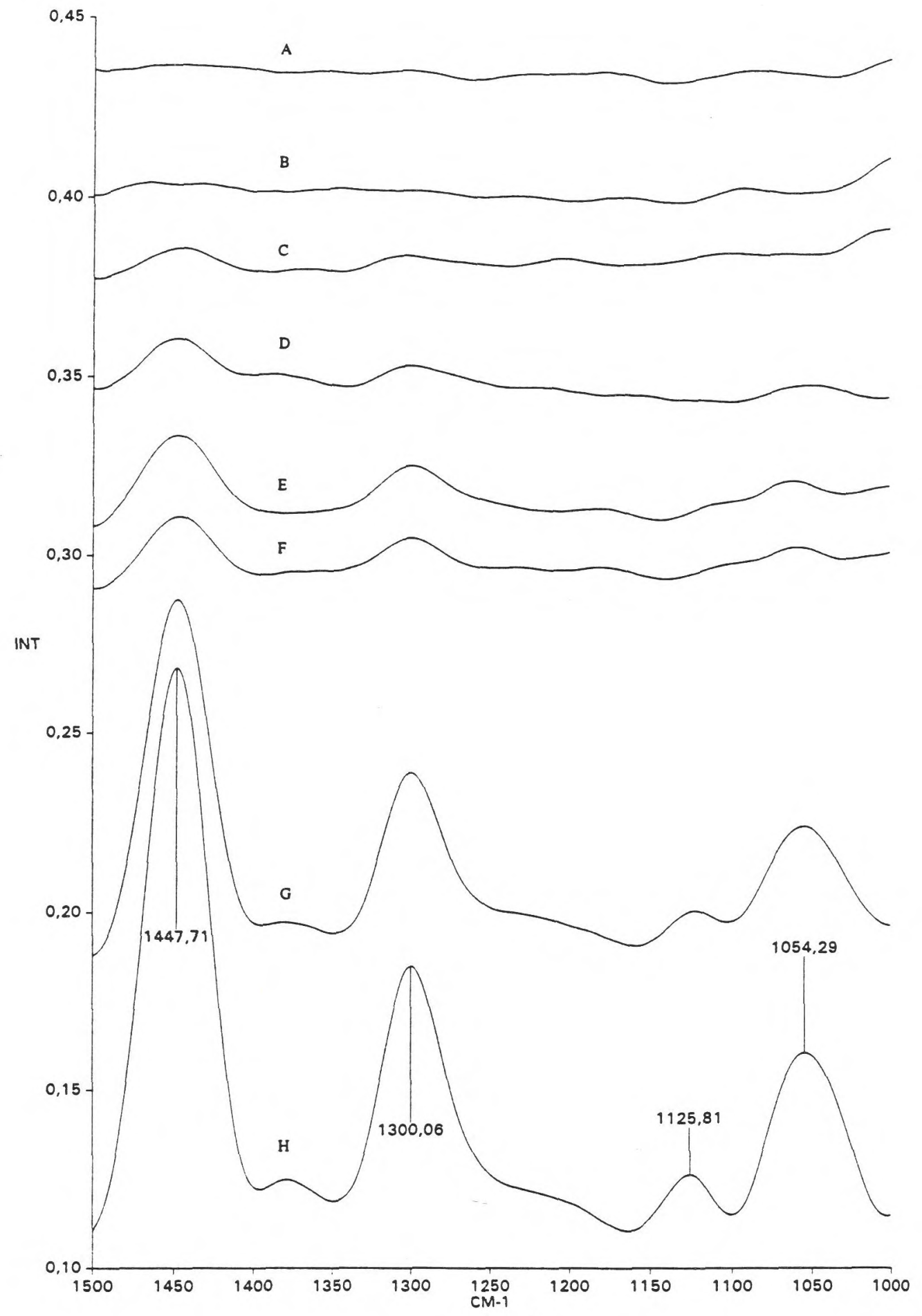

Fig. 5 


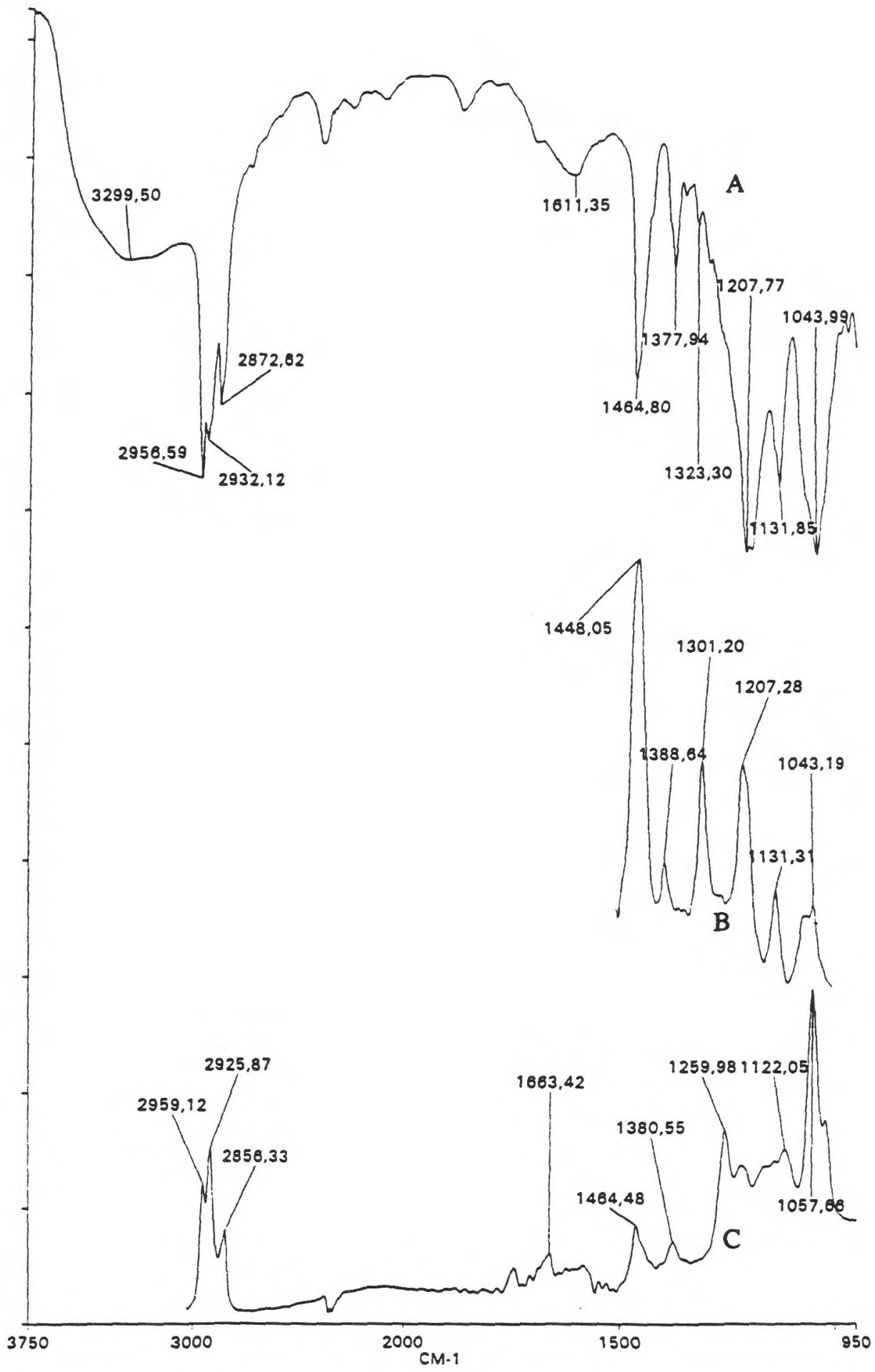

Fig. 6 


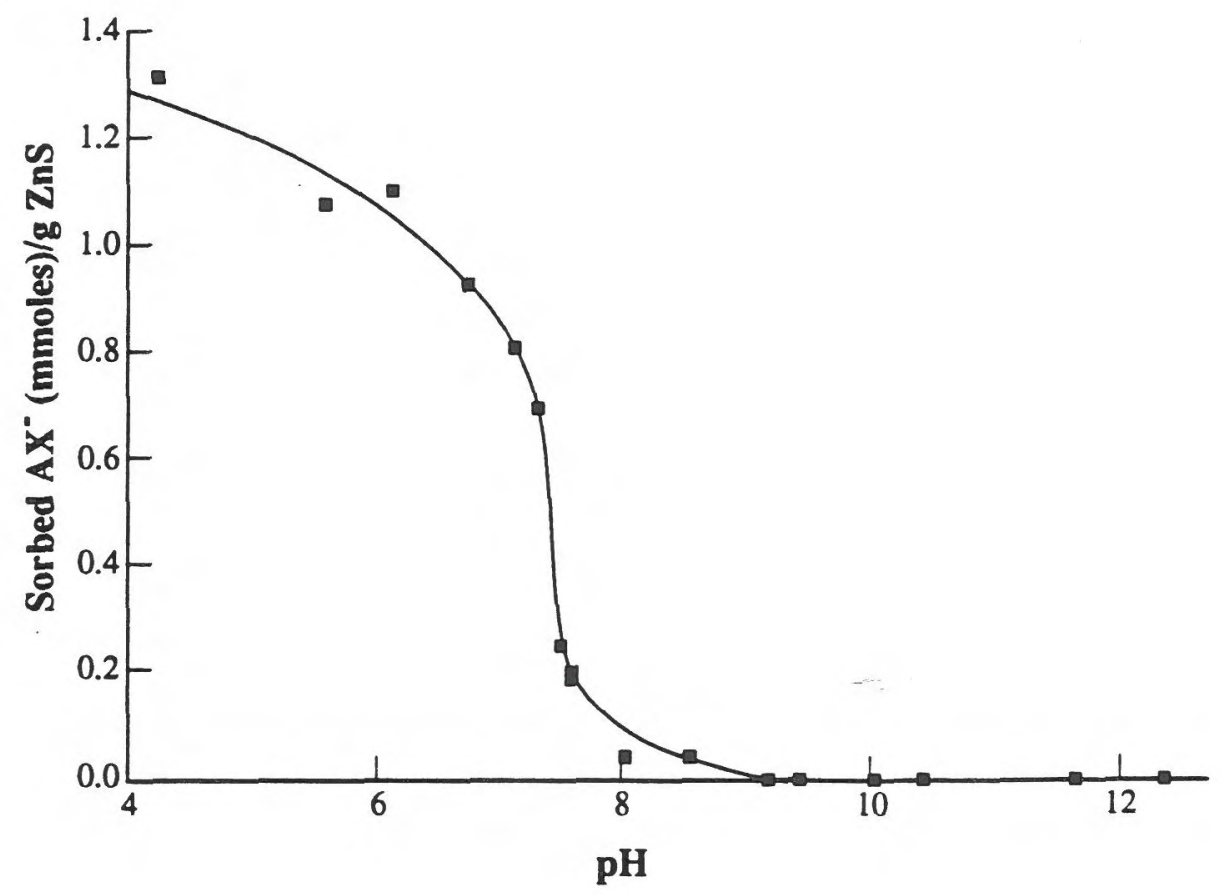

Fig. 7 
$\mathrm{TC} / \mathrm{mM}$ for $\mathrm{Zn}^{2+}=0.00$

$\mathrm{TC} / \mathrm{mM}$ for $\equiv \mathrm{SZn}=1.00$

$\mathrm{TC} / \mathrm{mM}$ for $\mathrm{AX}^{\circ}=10.0$

$\mathrm{TC} / \mathrm{mM}$ for $\mathrm{S}^{2-}=0.00$

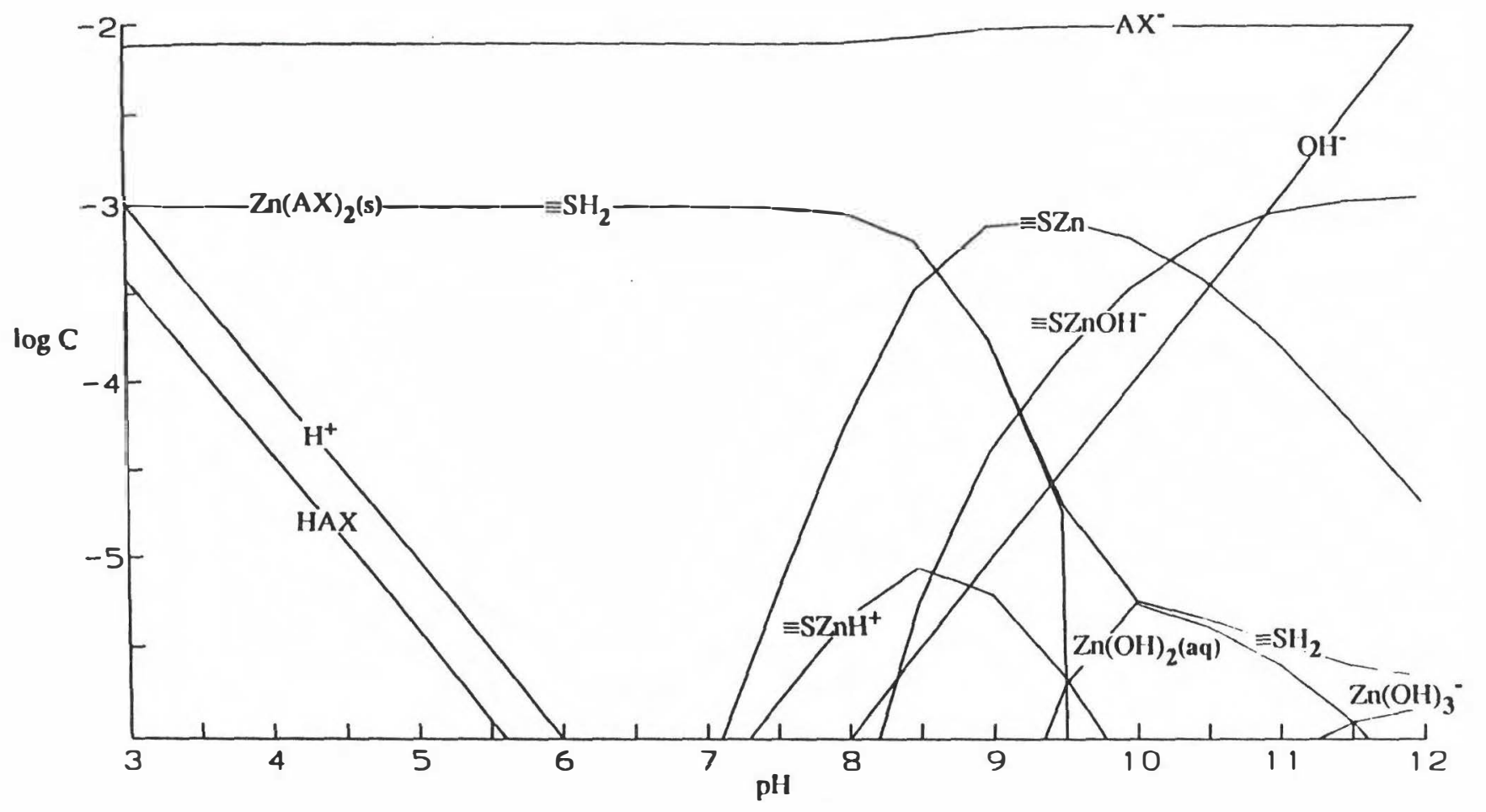

Fig. 8 